$12-2014$

\title{
Hits and Runs: Determinants of the Cross-Country Variation in the Severity of Impact from the 2008-09 Financial Crisis
}

Shane Dwyer

Chih Ming Tan

University of North Dakota, chihming.tan@UND.edu

How does access to this work benefit you? Let us know!

Follow this and additional works at: https://commons.und.edu/ef-fac

Part of the Economics Commons

\section{Recommended Citation}

Shane Dwyer and Chih Ming Tan. "Hits and Runs: Determinants of the Cross-Country Variation in the Severity of Impact from the 2008-09 Financial Crisis" (2014). Economics \& Finance Faculty Publications. 4.

https://commons.und.edu/ef-fac/4

This Article is brought to you for free and open access by the Department of Economics \& Finance at UND Scholarly Commons. It has been accepted for inclusion in Economics \& Finance Faculty Publications by an authorized administrator of UND Scholarly Commons. For more information, please contact und.commons@library.und.edu. 


\title{
Hits and Runs: Determinants of the Cross-Country Variation in the Severity of Impact from the 2008-9 Financial Crisis
}

\author{
Shane Dwyer and Chih Ming Tan*
}

May 6, 2014

\begin{abstract}
Recent empirical work on the 2008-09 financial crisis has found mixed results on the usefulness of indicators to explain the cross-country variation in the incidence of the crisis in non-originating countries. While some authors have found success with various indicators, Rose and Spiegel $(2009 a, b)$ find that almost no indicators are robust. We employ Bayesian model averaging (BMA) to verify Rose-Spiegel's conclusions under model uncertainty, confirming their findings. We then employ latent class models (LCM) to check the data for parameter heterogeneity. We find that there is substantial evidence of heterogeneity in the relationship between various indicators and crisis impact, both across individual indicators as well as across financial crisis episodes. In particular, a similar model fits the 1997 Asian financial crisis, although the coefficients change qualitatively in some cases. These results highlight the difficulty in employing simple linear models for early warning purposes, but demonstrate that there are robust indicators of cross-country variation in crisis impact across episodes, such as the pre-crisis growth in banking credit. A 2-class model explains the variation in crisis impact, where pre-crisis level of per-capita income assists in the prediction of membership in a particular class.
\end{abstract}

JEL Codes: F30, E65

Keywords: Financial Crisis, Contagion, Bayesian Model Averaging, Latent Class Models

*Dwyer: Department of Economics, Clark University, 950 Main Street, Worcester, MA 01610. Tan: Department of Economics, College of Business and Public Administration, University of North Dakota, Gamble Hall, 293 Centennial Drive, Grand Forks, ND 58202-8369. Corresponding author (Tan): chihmingtan@gmail.com. 


\section{Introduction}

Since the onset of the financial crisis of 2008, researchers have been quick to begin developing empirical models to both explain the variation in the severity of the crisis across countries, and to assess the ability of empirical models to predict future crises ${ }^{1}$. Much work has been done identifying and assessing the empirical robustness of individual indicators in terms of their ability to explain the differential economic impacts of various sources of crisis contagion, particularly on countries outside of the epicenter. Identifying which indicators serve as important determinants of crisis severity, in terms of sources of crisis contagion and domestic fundamentals, is an important first step towards building a model to predict future crises; i.e., an early warning system. It is the hope of researchers that building such early warning models (EWM's) will allow more accurate prediction of future crises. This must be done along three dimensions, as pointed out in Rose and Spiegel (2009a), including the identification of the most appropriate measures of the crisis itself, identification of the relevant indicators, and the determination of the appropriate time horizons for which changes in indicators may be suggestive of a potential crisis. Here, like in Rose and Spiegel (2009a,b), we are mainly concerned with the identification of relevant indicators, with a focus on the real costs of a crisis to economies.

A large body of literature exists regarding the development of EWM's in the context of previous crises ${ }^{2}$. Motivated by the latest crisis, a new body of literature reevaluating the usefulness of indicators has emerged. For example, Berkmen et al. (2009) provide one of the first attempts to empirically identify crisis correlates relevant to the 2008-09 crisis using cross-country regressions ${ }^{3}$. They find that a small set of variables can explain a large share of the variation in real economic impact, including cumulative credit growth, the degree of leverage, and exchange rate flexibility. They do not find a role for the level of international reserves, and mixed results for trade channels. Blanchard et al. (2010) examine a set of emerging market economies and use a simple theoretical model to characterize the potential role of trade and financial channels in transmitting the crisis. The authors employ simple cross-country OLS regressions and find evidence that short-term external debt and unexpected trading partner growth played a role in determining the severity of the crisis for emerging market countries. Somewhat weaker evidence is provided that the size of the current account also played a role. Similar to Berkmen et al. (2009), they were unable to find a role for international reserves.

\footnotetext{
1 The sources of the 2008 crisis are well documented, see Shoham and Pelzman (2011) and Claessens et al. (2010) for detailed reviews.

${ }^{2}$ See Frankel and Saravelos (2011) for a broad survey of the results of earlier investigations into EWM indicators.

${ }^{3}$ The authors focused on revisions to growth forecasts rather than actual growth rates, in part due to lack of available data at the time.
} 
Giannone et al. (2011), using various OLS specifications, examine the role of several measures of regulation in explaining variation in crisis severity across countries. They find evidence of a link between financial liberalization and vulnerability to shocks. Similarly, Lane and Milesi-Feretti (2010) use cross-country regressions and find evidence of a link between pre-crisis domestic financial and macroeconomic factors and various measures of total output, domestic demand, and consumption growth during the crisis. Particularly, evidence is provided of a link between credit growth and current account deficits with output decline on the financial side, and trade openness and the manufacturing share with output decline on the real side.

The above works are intimately related to a branch of the existing literature that focuses on contagion in terms of equity market portfolios. This literature has been helpful in identifying channels of transmission in the context of different exposures. For example, Beltratti and Stultz (2009) examine the returns of large banks before and during the crisis, finding a role for country-level regulation and supervision in determining the impact of the crisis on returns. Ehrmann et al. (2009) find that portfolios with more integration with US markets performed worse during the crisis. They also find evidence of a role for country level risk, particularly in terms of macroeconomic fundamentals, including the level of foreign exchange reserves, sovereign ratings, and current account positions. This result is not unlike that found from cross-country regressions done in the works discussed above. Eichengreen et al. (2009) examine differences in bank credit default swap (CDS) spreads, looking for movements of common factors. The authors find that bank performance overall tends to move together in normal times, but that the role of the common factor was greatly increased at the height of the crisis.

Recent works have seen serious attempts to identify indicators that could be potentially considered to have a robust impact on crisis transmission across a range of regression specifications. These studies are motivated by the desire to build a form of empirical early warning model. For example, Rose and Spiegel (2009a,b) use a Multiple Indicator Multiple Cause (MIMIC) model to test the robustness of a vast array of potential crisis indicators, both in terms of domestic vulnerabilities and international contagion. A key feature of the model employed here is that the severity of the crisis is treated as a latent variable reflected through various indicators, including crisis period economic growth, the change in the SDR (Special Drawing Rights) exchange rate, the change in sovereign credit rating, and the change in the value of the national stock market. Through a simple system of equations, the latent 'crisis severity' variable is linked to a wide range of potential indicators or causes. Examining each potential cause one by one within the MIMIC framework, the authors find few variables to be statistically significant. After several robustness tests, the authors conclude that there is little evidence that any proposed indicators can be empirically linked to variation in crisis incidence in a robust 
manner, casting serious doubt about the ability to construct an effective EWM with readily available data.

In a similar study, Frankel and Saravelos (2011) provide an extensive review of the financial crisis literature that predates the 2008-09 crisis, in an effort to avoid inclusion bias. Carefully scrutinizing the earlier EWM literature, they take a tally of variables that have been found to be significant in over 80 relevant studies. They then proceed to use their findings as a guideline in their own empirical investigation of the 2008-09 crisis. Similar to Rose and Spiegel $(2009 a, b)$, the authors estimate a large number of bivariate regressions using a host of crisis causes proposed in the literature. They differ, however, in that simple OLS is employed, using a single dependent variable at a time (they use several different dependent variables reflecting real and financial crisis manifestations to check robustness across specifications). Contrary to the work of Rose and Spiegel (2009a,b), the authors found several variables to be significant and robust indicators, including the real effective exchange rate and the level of international reserves.

In light of many of the previous studies cited above, Rose and Spiegel (2010) revisit their previous analysis with up to date data and methods. Following the methodology found in many of the above studies, Rose and Spiegel (2010) employ simple OLS and a single dependent variable (various definitions of crisis period growth), and check the robustness of their results to this improved data and standardized methodology. They are able to confirm their previous findings that very few, if any, of around 100 empirical indicators can be linked to cross-country crisis incidence in a robust fashion. Notably, any variables that appear to be statistically significant in a bivariate regression are often insignificant when additional variables are included simultaneously, casting doubt on the evidence provided by many of the studies relying on this approach.

While the above works suggest that multiple indicators may be potentially useful in explaining the cross-country variation in the incidence of the crisis in non-originating countries, they suffer from a range of methodological deficiencies. First, the vast majority of these studies do not properly account for the substantial amount of theory uncertainty inherent in the empirical analysis. An important reason for this uncertainty is the inherent open-endedness of theories of crisis transmission. The idea of theory open-endedness was articulated in Brock and Durlauf (2001) in the empirical growth context. Like growth theories, theories of crisis origination and contagion are open-ended in the sense that the inclusion of a particular theory of crisis transmission; e.g., growth in banking credit, does not automatically preclude other theories from also being included in the true model. The result is substantial uncertainty as to which variables (that proxy for theories) should be included in any given regression. Depending on the variables that are included, the coefficient estimates for crisis indicators of interest could (and often do) vary substantially across studies. 
A second weakness of the papers described above is that they typically assume a homogenous linear specification. That is, existing works investigating the effect of crisis indicators on contagion typically ignore the possibility that these indicators may exhibit substantively heterogeneous effects across different subsets of countries. A notable exception is Rose and Spiegel (2009a,b), who carried out several robustness exercises including splitting of the sample and including multiple regressors simultaneously. However, the sample splitting was carried out in an ad hoc manner, and it is unclear if the resulting subsamples truly reflect the component populations in the data. The possibility that complex nonlinearities and parameter heterogeneity are present in the data has generally not been thoroughly addressed.

We therefore have two aims in this paper. We first address the issue of model uncertainty. Specifically, we check the robustness of the results provided by Rose and Spiegel (2009a,b) and Rose and Spiegel (2010) to model uncertainty, applying Bayesian model averaging (BMA) to the updated dataset appearing in the latter paper ${ }^{4}$. BMA has been employed extensively in the growth literature to incorporate model uncertainty explicitly into inference; see, for example, Brock and Durlauf (2001), Fernandez et al. (2001). Rather than basing inference on a particular model or set of models, Bayesian model averaging bases inference explicitly on the entire space of possible models, circumventing the potential issue of a result being the outcome of a single specification or small set of specifications. A posterior probability distribution is estimated for each regressor, which is based on the calculated posterior model probabilities of each model that includes that regressor. Using this approach, our findings confirm the negative results from Rose and Spiegel (2010). We find, as they do, that the vast majority of variables are statistically insignificant, with low inclusion probabilities and large standard errors. We find that this result holds when altering several key parameters of BMA estimation, such as model and g-priors. These results contrast with those found in other studies, such as Giannone et al. (2011) who find a significant role for several variables including the size of the current account and the index of credit market regulations, when using BMA under similar model assumptions. Using a set of similarly defined variables in the model space, we do not find any robust indicators, having coefficient estimates with similarly large standard errors. The results of BMA analyses in this context are sensitive to the number of observations and the variables included in the model space ${ }^{5}$.

\footnotetext{
${ }^{4}$ This dataset is publicly available to download from Andrew K. Rose's personal website http://faculty.haas.berkeley.edu/arose/RecRes.htm\#GreatRecession.

${ }^{5}$ The replication includes the majority of variables used in the cited paper, including the top 5 reported variables by posterior inclusion probability. Some variables are dropped due to lack of availability or the reduction in the number of observations due to missing values. We have a balanced panel of 38 countries. Discrepancy could be the result of data revision, lost observations, or differing data sources. However, the difficulty in replication highlights the sensitivity of results to changes in the data, which is an issue in this context.
} 
We next investigate whether the lack of robust findings are an artifact of the homogeneity assumption by allowing for heterogeneity and nonlinearity within the context of latent class models (LCM). Latent class models are a form of finite-mixture models, which explicitly search the data for the existence of heterogeneous sub-populations by including a latent variable representing unobserved sub-populations or 'classes', and uses model selection criteria to guide the choice of the model with the appropriate number of classes. Between classes, any or all parameters may or may not be heterogeneous. The non-linearity we refer to with regards to this approach lies in its model-based sample splitting technique, where separate models apply to distinct classes, but a single linear model applies within a given class. Additionally, specific variables (covariates) may aid in determining the probability by which observations will belong to a particular class. We again employ the dataset of Rose and Spiegel (2010). In contrast with our findings in the linear context, our LCM results suggest that some indicators are potentially important determinants of variation in crisis incidence. Countries can generally be split into two classes, where the real impacts of various categories of explanatory variables are not identical between classes.

This modeling approach appears to reveal some interesting heterogeneous relationships in crisis impact across countries for the 2008-09 episode, although the heterogeneity in the model appears to change across crisis episodes. This result highlights the potential futility of simple linear models for early warning purposes. Put another way, there is a set of variables that do explain variation in the economic impact of financial crises, but the relationship of some variables with variation in crisis incidence appears to change across episodes. To arrive at this conclusion, we test the preferred specification fitting the 2008-09 crisis to data from the 1997 Asian financial crisis period. Heterogeneous relationships between the chosen set of variables and crisis impact persist, although for some variables the sign of the coefficients change across episodes. Of particular interest is the pre-crisis growth in banking credit variable, which is a robust indicator across specifications and crisis episodes, maintaining its qualitative and quantitative interpretation. Similarly, a 2-class model best fits crisis experience across the sample periods, where pre-crisis level of per capita income assists in predicting which countries belong to either class.

Using the LCM modeling approach, we find that the level of pre-crisis income influences the probability of belonging to a particular class, with wealthier countries more likely to belong to Class 1 , and poorer countries more likely to belong to Class 2 . Within classes, some parameters are heterogeneous. We provide evidence that particularly strong indicators of crisis period output impact include the growth in pre-crisis credit provided by the banking sector, whether or not a country is a major commodity exporter, the pre-crisis inflation rate, the size of the pre-crisis current account, and limited evidence of a role for 
pre-crisis stock market capitalization and credit market regulation. In many cases the coefficients for these indicators are significantly different between classes. We also provide evidence that other indicators are empirically relevant, but weaker in terms of statistical significance. Specifically, pre-crisis growth in banking credit had a negative impact on growth for both classes, but this effect is larger in magnitude for Class 2 . The effect of CPI inflation was either beneficial or at least nonnegative for countries in Class 1 , while it harmed the growth performance of countries in Class 2. Similarly, status as a commodity exporter is associated with higher growth rates for Class 1 but lower growth for Class 2. The degree of stock market capitalization preceding the crisis appears to have been harmful for Class 2 but beneficial to Class 1 . Several variables regarding the state of the financial sector are relevant to Class 2 , but exhibit a statistically weaker relationship to Class 1. This leads us to conclude that parameter heterogeneity is important to the crisis model, and that great care should be taken regarding the existence of these relationships when building early warning models of crisis incidence and contagion.

The paper proceeds as follows. Section 2 introduces Bayesian model averaging, the data set with which it is applied, and the results from that exercise. Section 3 introduces latent class modeling and the results from estimation using that particular framework. Section 4 provides tests of robustness including the fitting of the model to an alternative crisis episode, and section 5 concludes.

\section{Model Uncertainty}

Rose and Spiegel (2010) find that almost none of roughly 100 indicators can be linked to cross-country crisis incidence in a robust manner. Our first task is to check whether or not these particular results are robust to model uncertainty. A look through the crisis literature reveals the uncertainty in specifying an appropriate empirical model of financial crises. The simple theoretical model used by Blanchard (2010) provides some guidance as to the type of variables we may wish to focus on in an empirical analysis, but its simplicity and ad-hoc nature leads us to believe that there may be far more sources of contagion to consider, and the theory to motivate each and every one either doesn't yet exist or cannot be combined into an all-encompassing crisis model that explains the different experience of each individual country across the globe. Additionally, the inclusion of one theory of crisis contagion should not logically exclude other theories from being included in the model space, as researchers have provided evidence in favor of, or contradicting, various theories. Lastly, an additional attractive feature of BMA is that it allows researchers to consider many variables even when the potential number of observations is relatively small, as is usually the case for cross-country regression analysis. Taking these concerns into consideration, we choose to employ an empirical methodology that explicitly accounts for model uncertainty known as Bayesian model averaging (BMA). 
To summarize the BMA methodology, we begin by considering a simple linear regression model given by equation (1):

$$
y=\alpha+Z_{j} \beta_{j}+\epsilon
$$

Where $y$ is a vector of responses for $\mathrm{n}$ individuals regressed on an intercept and an $\mathrm{n} \mathrm{k}$ matrix of variables, and $\beta$ is the vector of $\mathrm{k}$ regression coefficients. BMA allows us to consider the entire set of $\mathrm{k}$ variables, including all subsets. Therefore, BMA considers a set of $2^{\mathrm{k}}$ possible models which differ from each other by the set of included regressors. Denoting any individual model (combination of regressors) as $M_{j}$, the prior probability of any one model being the 'true' model is given by (2):

$$
P\left(M_{j}\right)=p_{j}, j=1 \ldots 2^{\mathrm{k}}, p_{j}>0 \text { and } \sum_{j=1}^{2^{k}} p_{j}=1
$$

The importance of (2) lies in the implicit notion that the 'true' model is located within the model space. This formulation requires a statement of the prior probability of each individual model in the model space. With no substantial prior information to give weight to any one model over another before estimation, we assume the random hierarchical prior suggested by Ley and Steel (2009). This prior was designed to minimize the influence of prior probabilities on posterior results. As a robustness check, we also employ a uniform prior over models thereby giving each model in the model space an equal prior weight. BMA allows us to then explicitly incorporate model uncertainty by treating a quantity of interest $\Delta$ as an average of the posterior distributions of that quantity estimated within each model, weighting each estimate by the posterior model probabilities. The probabilities are calculated according to Baye's rule. This process is represented by equation (3):

$$
P_{(\Delta \mid D)}=\sum_{j=1}^{2^{k}} P_{\left(\Delta \mid D, M_{j}\right)} P\left(M_{j} \mid D\right)
$$

$D$ represents the data, while the quantity of interest $\Delta$ may be any estimated parameter such as the $\beta$ parameters for each variable. The summation of the posterior probabilities of the inclusion of a variable under each particular model containing that variable provides the marginal posterior probability of inclusion. This is the essence of BMA as a method for incorporating model uncertainty.

In terms of our application, the dependent variable used is 2008-09 economic growth reported by the Economist Intelligence Unit, and the model space includes sets of predictors chosen by various categories of international contagion factors and domestic macroeconomic fundamentals. The data come directly from Rose and Spiegel (2010), 
including a rather comprehensive collection of crisis correlates suggested in the literature on the subject. These variables fall under many categories, of which are organized in Table 1 below. The data set covers 107 countries, although missing data reduces the effective number of observations in our empirical analysis to varying degrees. The criteria for a country's inclusion in the analysis is a 2003 GDP per capita of at least $\$ 10,000$. For smaller nations, those with a population of at least one million and a real GDP per capita of at least $\$ 4,000$ are also included. Table 2 reports the full sample of countries.

The first category of variables include simple controls for country size and income reflected by the log of real GDP per capita and the log of total population in 2006. The second category of independent variables, 'financial policies', includes variables reflecting the institutional structure of the financial sector, such as the degree of credit market regulation variable from the Economic Freedom of the World (EFW) Index. Some other key variables falling under this category include 'official supervisory power', 'overall capital stringency', and 'power to declare insolvency'. Most of these variables are of the index form. These variables are found in a branch of the literature that considers the role of regulation in crisis exposure, such as Giannone et al. (2011).

The next set of categories reflect the characteristics of the financial sector. Category 3 , or 'financial conditions', includes variables that signal the health and level of development of the financial sector. Some of the key variables in this category include the 'private sector domestic credit share of GDP', the 'change in banking credit from 20002006', the 'change in private credit from 2000-2006', the 'bank non-performing loan ratio', 'bank capital', and 'bank liquid reserves'. These variables are commonly found in empirical work that considers financial sector health in generating exposure to crises.

Categories 4-6 reflect international and domestic macroeconomic forces such as asset prices, macroeconomic policies, and imbalances. Specifically, category 4 includes variables reflecting the movement of asset prices leading up to the crisis, such as the change in real estate prices from 2000-2006 and stock market capitalization between 2000-2006. These variables are important to the latest crisis, as several key countries experienced housing bubbles particularly. Category 5 reflects international imbalances between countries. Variables under this category are often sourced from the World Bank or IMF indicators databases and reflect such values as the size of the current account as a percentage of GDP, the type of exchange rate regime employed by a nation, total reserves as a percentage of GDP, the change in the real effective exchange rate between 2000-2006, and external short-term debt as a percentage of GDP. Category 6 covers Macroeconomic policies, such as the level of CPI inflation, a variable indicating whether or not a country's central bank is an inflation targeting regime, a variable indicating whether or not a country is part of a monetary union, total debt as a percentage of GDP, the GDP share of M2 or M3 money, and the sovereign credit rating as measured by Moody's. 
The final set of categories cover geography, institutions, and trade/financial linkages which are often found in the broader economic growth literature. Category 7 covers institutional factors specific to countries, such as the EFW index of credit/labor/business regulations, the Polity Index in 2006, various measures of regulatory quality, rule of law, political rights, voice and accountability, control of corruption, property rights, status as a financial center, total government size as a share of GDP, and status as an advanced economy. Category 8 covers simple geographic controls, such as the log of latitude, regional dummies, and status as a commodity exporter. Finally, category 9 includes variables representing financial and trade linkages with the crisis epicenter (US) including variables measuring the degree of countries' exposure to US assets, equity, long and short debt, and trade. These variables represent the linkages and potential sources of contagion stemming from economic ties to the epicenter of a financial crisis, which is the US in this case.

The BMA analysis is estimated using the 'hyper' g-prior as well as the 'unit information prior' (UIP) for comparison. Several variables from each category discussed above are included in the model space. We note that some variables have to be excluded because the limited number of observations they possess severely limits the information that can be used for estimation 6 . We report results using the random/hierarchical model prior as suggest in Ley and Steel (2009). Tables 3 and 4 provide the results of BMA estimation using the 'UIP' and the 'hyper' g-prior, respectively. It is immediately clear that the selection of indicators show little statistical significance, even when addressing model selection issues using BMA in this crisis model context. With a 'UIP' g-prior, no variables have an estimated posterior inclusion probability above $50 \%$ and not a single individual regressor is statistically significant. This result is similar to the negative findings of Rose and Spiegel (2009a,b) and Rose and Spiegel (2010), arising from the limitations of linear and homogeneous models used in those papers, as we demonstrate in the next section. The results do not change significantly when using a 'hyper' g-prior, with only one variable having a posterior inclusion probability above $50 \%$ and once again not a single statistically significant regressor. As previously mentioned in the introduction, these results also contrast those by Giannone (2011) who find a statistically significant influence of several variables when using BMA analysis?

In addition to the results reported in Tables 3 and 4, several alternative g-priors, model priors, and modifications to the model space were attempted but the results remain robustly negative. Specifically, the 'BRIC' or benchmark g-prior and the 'EBL' or local

\footnotetext{
${ }^{6}$ Typically, we include no more than a few representative variables from the categories discussed. Alterations to the model space include selecting different variables from each category.

${ }^{7}$ The BMA analysis in this section includes slightly differing sets of variables from the Giannone et al. (2011) paper, although a replication including most of the variables from their analysis was part of the robustness checks we conducted.
} 
empirical Bayes g-prior were used to further check the robustness of the results, which do remain robust. The reported results are robust still to the use of a uniform model prior. Additionally, different versions of the model space were tested, where variables that are similar in definition and category are used in substitution. Regardless of such alterations to the model space, model prior, and g-prior, the reported results hold. In the interest of space, we report only the results using a representative model space and both the 'UIP' and 'hyper' g-priors and the random/hierarchical model prior.

\section{Latent Class Models}

Having checked the robustness of the results of Rose and Spiegel $(2009 a, b)$ and Rose and Spiegel (2010) to model uncertainty, we now proceed to revisit the data under a new set of assumptions. To address the potential heterogeneity in modeling crisis experiences across countries, we employ the use of latent class models (LCM) ${ }^{8}$. We begin by introducing LCM analysis, in particular the latent class regression model.

Latent class models are a form of finite mixture models which identify segmentation in a sample through the use of categorical latent variables which represent a 'cluster' or 'class'. The advantage of LCM models over traditional cluster or segmentation models lies in the model based approach that LCM uses to classify 'cases' into the appropriate segment. LCM software allows the estimation of various forms of LC analysis, but for our purposes we employ the LC regression model. The key features of the LC regression model can be stated as follows. Like a traditional regression model, LC regression is used to predict a single dependent variable as a function of a set of predictors. However, the LC regression model contains a K-category latent variable representing the unobserved homogeneous subpopulation or cluster. Furthermore, by identifying different segments or clusters in the data, we are able to relax the assumption that a single model exists for each individual cluster. Specifically, LC regression allows parameters to vary between clusters as well as the set of included variables. In particular, LCM models allow the $\beta$ parameter of any indicator to be constrained to zero for one or more classes, in practice allowing different variables to appear in each model for each class, with or without overlap. LC regression models also allow the use of covariates to aid in the identification and description of each cluster.

For our purposes, a plausible interpretation of a k-cluster cross-country crisis model would be a model that assigns each country in our sample to a different category of structural exposure or vulnerability to economic impact (in terms of growth) according to posterior membership probability, estimated directly from the model. To this end we are able to address heterogeneity in our sample according to various levels of financial crisis exposure or vulnerability, specifically in non-originating (non-US) countries. The addition

\footnotetext{
${ }^{8}$ Estimation of LCM was carried out using LatentGOLD 4.0.
} 
of covariates aids in description of clusters and the estimation of posterior membership probabilities. In the following paragraphs we will discuss how LC regression models are estimated.

The general LCM model identifies 'classes' or 'clusters' through the use of single or multiple response variables or 'indicators', and optionally through the use of covariates. The basic probability structure is given by equation (4) where $y$ is a vector of $T$ response variables, or indicators, for individual $\mathrm{i}$, and $z$ is a vector of $\mathrm{j}$ covariates. $X$ represents the $\mathrm{K}$ category latent variable or cluster.

$$
f\left(\mathbf{y}_{i} \mid \mathbf{z}_{i}^{\text {cov }}\right)=\sum_{x=1}^{K} P\left(x \mid \mathbf{z}_{i}^{\text {cov }}\right) \prod_{t=1}^{T} f\left(\mathbf{y}_{i h} \mid x\right)
$$

The default assumption is that given class membership, each indicator is mutually independent. This assumption can be relaxed, however, if one groups indicators into $\mathrm{H}$ sets. The LC regression model, as we implement it, involves some modifications to the framework given in (4). Most notably, the LC regression model makes use of a single dependent variable.

The chosen dependent variable for our model is 2008-09 economic growth from the Economist Intelligence Unit ${ }^{9}$. The LC regression model makes a distinction between the set of independent variables $z$ used to predict the dependent variables (predictors), and the set of variables used to identify cluster membership (covariates). The set of $z$ variables that are used as predictors in our models include a large collection of potential crisis causes and contagion suggested by the early warning literature, measured in 2006 or earlier to avoid issues of endogeneity. These variables fall under many categories, of which are organized in Table 1 below. Some of these variables can be considered direct sources of contagion, such as financial and trade variables, while others control for heterogeneity in institutions, geography, policies, etc. When we choose to include a covariate, we use the log of 2006 GDP per capita ${ }^{10}$. Most of these variables can be found in much of the cross-country empirical work on the 2008-09 financial crisis. The data set covers 107 countries, although missing data reduces the effective number of observations in our empirical analysis to varying degrees. The criteria for inclusion in the sample is identical to that appearing in the subsection on BMA above.

The general probability structure specific to the LC Regression model is given by equation (5):

\footnotetext{
${ }^{9}$ Rose and Spiegel (2010) note that the majority of the recent financial crisis literature focuses primarily on growth effects, so we focus our attention on the 08-09 growth rate variable as the dependent variable in our BMA and LCM regression analyses.

${ }^{10}$ Many variables were tested for use as a covariate, but the log of 2006 GDP per capita was by far the most consistent and robust covariate.
} 


$$
f\left(\boldsymbol{y}_{i} \mid \mathbf{z}_{i}^{\text {cov }}, z_{i}^{\text {pred }}\right)=\sum_{x=1}^{K} P\left(x \mid \mathbf{z}_{i}^{c o v}\right) \prod_{t=1}^{T_{i}}\left\{f\left(y_{i t} \mid x, \mathbf{z}_{i t}^{\text {pred }}\right)\right\}^{v_{i t}}
$$

When using continuous dependent variables, LC Cluster models make use of the following linear predictor given by equation (6):

$$
\eta_{x, z_{i t}}=\beta_{x 0}+\sum_{q=1}^{Q} \beta_{x q} \cdot z_{i t q}^{p r e d}
$$

$\beta_{x 0}$ is the class specific intercept value and $\beta_{x q}$ is the class specific regression coefficient for predictor $q$. This equation defines the regression model specific to each latent class. LatentGOLD software also allows the feature of imposing restrictions on the parameters, such as class independent restrictions or no effect of a particular predictor on one or more classes.

The inclusion of covariates allows us to model the value of the latent variable as being determined from a joint multinomial distribution. Therefore, the probability of membership in a given cluster is estimated using the standard multinomial logit model appearing in equation (7):

$$
P\left(x \mid z_{i}^{c o v}\right)=\pi_{x \mid z_{i}}=\frac{\exp \left(\eta_{x \mid z_{i}}^{t}\right)}{\sum_{x^{\prime}}^{K} \exp \left(\eta_{x^{\prime}, z_{i}}^{t}\right)}
$$

The linear term in this multinomial logit model is specified by equation (8):

$$
\eta_{x \mid \mathbf{z}_{\mathbf{i}}}=\gamma_{x 0}+\sum_{r=1}^{R} \gamma_{x r} \cdot z_{i r}^{c o v}, \text { where } \sum_{x=1}^{K} \gamma_{x r}=0
$$

The probability of membership in a given cluster $x$ is conditional on the value of each covariate $z$.

To estimate the parameters specified in equations (6) and (8), LatentGOLD software makes use of the Maximum Likelihood method with the assistance of the Newton-Raphson and Expectations Maximization (EM) algorithms, essentially treating the existence of latent classes as a missing data problem ${ }^{11}$. The standard procedure for LCM estimation is to specify a range of classes, eg. 1-6, for which LCM estimates each model individually and reports a range of information criterion statistics for comparison and model selection. For our purposes, since we will employ a relatively small sample typical of cross-country datasets, we select the best model according to either the $\mathrm{BIC}$ or the $\mathrm{AIC}_{\mathrm{c}}$ criterion, choosing

\footnotetext{
${ }^{11}$ Further details of LCM estimation, including the equations above, can be found in the Latent GOLD 4.0 technical manual.
} 
the model with the lowest reported statistic ${ }^{12}$. Our particular procedure for this paper is to first estimate LCM models using individual predictors one by one, with and without the use of covariates, and then estimate larger models with simultaneous sets of predictors based on the strength of results from the initial exercise.

We begin our empirical LCM analysis by following a procedure similar to that conducted in Frankel and Saravelos (2010), in which they examine each potential indicator one by one in the context of LC Regression estimation. To this end, we search for potential heterogeneity in the relationship between crisis period growth and each potential source of crisis contagion in the context of bivariate LCM regressions, using 4 baseline models. The first model uses only the predictor of interest without the aid of covariates. The second model includes the log of 2006 GDP per capita as an additional covariate, the third includes GDP per capita as an additional predictor rather than a covariate, and the fourth and final model includes GDP per capita as both a predictor and a covariate.

Tables 5.1-5.4 report the results from this exercise. There are several pieces of information to take from the tables. First, we report the model selection choice according to both the BIC and $\mathrm{AIC}_{\mathrm{c}}$ information selection criterion. For example, for the '2006 current account as a percentage of GDP' variable, the best model according to both information criterion statistics is a one class model except for case 2 (GDP per capita included as a covariate), where a 2 class model provides the best fit. The adjacent columns report whether or not the variable was significant at the $10 \%$ level or better in a 1-class, 2 -class, or 3-class LC Regression model. Reporting "insign." (in red) means that the variable was insignificant for all classes, "sign." (in dark blue) means the variable is significant for all classes, and 1 class significance means that the variable was significant for at least 1 class (in light blue). This exercise serves more than one purpose. The first is to rule out variables that provide little reduced-form evidence of being relevant indicators in LCM models of crisis incidence, effectively narrowing the large set of potential candidates. Second, we search for heterogeneity in contagion relationships by seeking whether or not any crisis indicators have parameters that are statistically significantly different between the classes identified by the LCM model. In other words, we search for evidence that the relationship between any particular variable and crisis performance may differ between classes. Lastly, we try alternate specifications of the model to check the robustness of these results.

Tables 5.1-5.4 provide several interesting results. Firstly, it is shown that many variables exhibit a statistically significant relationship with crisis period growth when used in a 1-class bivariate LC Regression. When a 2 class or 3 class model is estimated, this set

\footnotetext{
${ }^{12}$ The justification for $\mathrm{AIC}_{\mathrm{c}}$ as an appropriate small sample information criterion is given in Burnham and Anderson (2004).
} 
of significant variables shrinks, but many are still significant for at least 1 class. When estimating bivariate regressions, most information criterion suggest 1 class models, although the notable exception is with case 2 (log of GDP per capita included as a covariate), where many regressions suggest 2 class models. A notable example of this would be the current account/GDP ratio, which is significant in every model estimated and suggests a 2 class model for case 2 when selecting according to either BIC or AIC c.

To summarize the key findings from Tables 5.1-5.4, we note that variables related to conditions in the financial sector tended to be more robustly significant across specifications, such as 'bank ownership', the 'bank non-performing loan ratio', bank claim/deposit ratio', 'change in banking credit', 'credit market regulations', 'foreign bank competition', and 'bank liquid reserves/asset ratio'. These variables appear to be relatively robust indicators of crisis period growth performance. A second set of variables that tended to perform relatively well included institutional/political variables such as the 'dummy for advanced economy', the 'dummy for commodity exporter', 'civil liberties', 'government effectiveness index', the 'polity index', 'property rights', 'regulatory quality', 'rule of law', and the 'voice \& accountability index'. Some variables related to macroeconomic fundamentals performed relatively well also, including the 'size of the current account', 'external debt', 'net government borrowing/lending', and 'average growth of trading partners in 2008-09'13. Other variables that performed relatively well included 'real housing price appreciation 2000-2006', 'log of latitude', and a few select regional dummies. Surprisingly, several variables that have been reported in the literature as being important or relevant fail to perform well in bivariate regressions. These variables include the 'dummy for fixed exchange rate regime', the 'change in the real effective exchange rate', the 'percentage of total trade that is conducted with the USA', the 'dummy for financial center', and 'total reserves/GDP'. 'Market capitalization between 2003-2006' also provides fairly weak results.

Perhaps the most surprising result from the tables is the relatively weak explanatory power of variables related to exposure/contagion from the US. All the US TIC variables related to debt/assets/equity appear to have little power in explaining the variations in crisis impact. Similarly, exposure to US trade appears to have little explanatory power as well. This result is interesting because it suggests that contagion (in terms of exposure to the epicenter of the crisis) effects were not important in determining the impact of the crisis across countries. Rose and Spiegel (2009b) found this to be the case, and we once again corroborate this result. It is likely that macroeconomic fundamentals and financial characteristics were more influential in determining the variation in the severity of the crisis. It is well documented that the resulting panic at the

\footnotetext{
${ }^{13}$ The net government borrowing/lending and net government debt variables were added to the Rose and Spiegel (2010) data from the publicly available IMF Indicators database.
} 
height of the crisis seized up access to credit in domestic and international markets, which carried over to international trade and likely caused much of the economic damage, rather than individual exposures to US markets, a claim that seems to be supported by the data.

Another key implication of the table is that it provides evidence of heterogeneity among indicators and their relationship with crisis period growth. As previously indicated, if one looks at the current account variable, it is shown that when estimating a model including the current account as a predictor and the log of GDP per capita as a covariate, a 2 class model provides the best fit. This predictor is strongly significant for both classes and is statistically different between classes. This provides evidence that the relationship between the level of the current account and crisis period economic growth is heterogeneous across 2 different groups or 'classes' of countries. The log of income per capita helps us to predict which class individual countries belong to ${ }^{14}$.

Using the results from Tables 5.1-5.4, we continue our analysis by estimating LC regression models using variables that have shown at least some success in the bivariate analysis. Since we have little theory from the literature to help us guide our specification, we admit this approach to variable selection is somewhat ad-hoc. Nonetheless, we estimate a series of crisis models using different sets of variables, similar to other empirical papers in the EWM literature. BIC and $\mathrm{AIC}_{\mathrm{c}}$ statistics guide model selection. The results of this exercise are reported in Table 6.

Table 6 provides the results from several versions of latent class financial crisis regression models, the $\mathrm{BIC}$ and/or $\mathrm{AIC}_{\mathrm{c}}$ criterion guide us toward the choice of 2 class models ${ }^{15}$. Under the column 'Model 1' we report the coefficients on the parameters of a 2 class model that includes the current account, the growth in banking credit, inflation, and a dummy for major commodity exporter as the included set of explanatory variables, and the $\log$ of GDP per capita as a covariate. This column is divided into two sub columns, one for each class. 'Profile' reports the expected cluster size according to posterior membership probabilities estimated for each observation (country). The R-square statistic is reported for each individual class as well as for the overall model.

We can see from the results of model 1 that a more favorable current account position had a positive effect on growth outcomes for both classes, although the effect is much greater for class 2 . To be specific, on average, a $10 \%$ increase in a country's current account/GDP ratio is associated with a $.7 \%$ loss to the crisis period growth rate for countries in class 1 and a $5.8 \%$ decrease in the growth rate for countries in class 2 . This is

\footnotetext{
${ }^{14}$ The log of GDP per capita enters as a statistically significant covariate in nearly all LCM models in which it is included.

${ }^{15}$ Appendix 1 provides the classification of countries that each model generates, as well as the mean growth and income of each class. Some of the variation in countries listed comes from countries being added/dropped depending on the included variables, due to missing observations.
} 
an example of parameter heterogeneity demonstrated by the effect of the current account on different subpopulations in the sample, as the coefficient is statistically significantly different within, as well as between, classes. Pre-crisis growth in banking credit had a significantly negative effect on crisis period growth for both classes, with the magnitude of the effect significantly larger for class 2. A 10\% larger increase in banking credit from 2000-2006 is associated with $.391 \%$ loss of crisis period GDP growth on average for countries in Class 1 and a 3.345\% loss in crisis period growth for those in class 2. CPI inflation seemed to slightly weather the crisis for class 1, while hurting growth performance in class 2. The interpretation of the coefficient is analogous to that of the banking credit variable Lastly, being a significant commodity exporter was beneficial to growth performance in class 1 , but detrimental to countries in class 2 . Specifically, being a major commodity exporter resulted in a $3.363 \%$ higher crisis period growth rate on average for countries in class 1 , and $3.95 \%$ lower growth for those in class 2 . The coefficients on the covariate (log of 2006 real GDP per capita) tell us that richer countries are more likely to belong to class 1 and poorer countries more likely to belong to class 2 . This should not be interpreted as a completely deterministic relationship, as some poorer countries can belong to class 1 while it is similarly possible for richer countries to belong to class 2 , as the covariate values help determine probabilities of membership. In summary, this baseline model demonstrates the parameter heterogeneity that is possible when using latent class models.

To achieve a more parsimonious specification, the LatentGold 4.0 software allows us to place restrictions on certain parameters on a class by class basis. For example, we can restrict the coefficient of the current account variable to be zero for class 1 in model 2, which we do (after estimating an unrestricted model), since the coefficient estimate is now statistically insignificant in this new specification before imposing the restriction. We impose restrictions like this, along with cross-class parameter equality restrictions, on certain specification across the models we estimated. The restrictions are imposed after estimating an unrestricted model, and are justified by the resulting improvement in the information criterion statistic.

Model 2 demonstrates this fact, where we include the degree of credit market regulation as an additional predictor. The results of this model are reported under the column 'Model 2'. Estimation of this model with credit market regulation included causes the current account variable to enter insignificantly for class 1 . Credit market regulation also enters insignificantly for class 1 but significantly for class 2 . The credit market regulation variable is a 10 point scale index variable where higher values represent more liberal credit markets. For class 2, a 1 point increase in the credit market regulation index is associated with a $3.34 \%$ lower crisis period growth rate, on average. Other than the 
parameters that have been restricted to zero, the sign of the remaining coefficients is preserved, although their magnitudes change to varying degrees.

Model 3 adds the degree of stock market capitalization from 2003-2006 as an additional predictor. Surprisingly, this variable enters positively for class 1 and negatively for class 2. Models 4 through 6 add selected financial variables (the bank claim/deposit ratio and the bank nonperforming loan ratio) found to be significant in the bivariate regression exercise. These variables are significant for class 2 but insignificant for class 1 . Models 7 and 8 add an institutional indicator, the voice $\&$ accountability index. Once again, this variable enters as a significant predictor for class 2 but not for class 1 . Model 8 includes the log of GDP per capita in 2006 as a predictor as well as a covariate, and we see that including this measure results in an insignificant coefficient for both classes, and does not change the results for other included predictors. We estimated several other models adding additional predictors from the long list of Tables 5.1-5.4, but these variables were generally insignificant and did not impact the results.

Appendix 1 includes tables providing the predicted class membership for all countries under each estimated model. The countries are assigned classes based on the estimated probability of belonging to a particular class, which is a function of included variables. As demonstrated in the tables, the assignment of countries remains relatively stable across specifications. Class 1 is made up of countries with a relatively larger mean GDP per capita and a lower average crisis period growth rate, typically in the negative region. Countries in class 2 tended to be made up of a smaller selection of poorer, emerging market countries that grew positively on average during the crisis. Some of the small differences in means and country assignments across specifications can be attributed to the dropping out or reentry of some countries due to the particular specification, on the part of missing observations.

The main implications from Table 6 are that there is relatively abundant evidence of parameter heterogeneity among predictors of crisis period growth performance, and that a 2 class model provides the best fit for prediction, given the currently available data. The growth in banking credit from 2000-2006 appears to be the most robust predictor of variation in the growth impact of the 08-09 crisis, having very similar coefficients in sign and magnitude across specifications. There is evidence that pre-crisis inflation and the degree of credit market regulation are important predictors for class 2, although the magnitude of the coefficient is not as consistent across models. Evidence is provided that a country's status as a major commodity exporter is also an important predictor for both classes across models. There is some evidence that financial and institutional variables such as indicators from the banking sector and the voice \& accountability index may also play a role in predicting crisis period growth performance. These results contradict those found in the BMA analysis conducted above, suggesting that the standard linear models 
often found in the EWM literature fail to capture the heterogeneous relationships inherent in the data.

\section{Robustness Checks}

It is worth noting that the effects of the 2008-09 crisis lingered for many advanced countries after the initial global downturn. In particular, many European countries experienced a double-dip recession, where growth fell into the negative territory once again during the year 2012. As an additional check, we adjust the dependent variable to 2012 economic growth, while keeping the same baseline specification. The results from this exercise are provided in Table 7. Unlike the 2008-09 period, a one class model provides the best fit, suggesting that heterogeneity is not a factor in modeling the lingering effects well after the initial crisis phase. Buildup in credit and status as a commodity exporter do still have some explanatory power with regards to economic performance during this period, but the power of the baseline model is reduced.

The latent class regression models of Table 6 provide a reasonably well fit model of the 2008-09 financial crisis. If the indicators identified are to be considered truly useful for prediction of future crises in EWM models, they must have out of sample predictive power. As a first test of this, we attempt to fit the same baseline specification (model 1 from Table 6) to an alternative crisis period. We choose the period of the last major global financial episode, the 1997 Asian financial crisis. If the model appears to similarly fit the alternate period, there may be substance to the claim that the model may be useful in predicting future crises. Table 8 provides a series of robustness checks in which the baseline specification is re-estimated using both revised (updated) data as well as an alternate sample period, the 1997 Asian crisis. We also check the model to the use of de-trended real GDP growth rates. We look at de-trended rates when introducing the 1997 crisis period for a couple of reasons. Firstly, the overall impact of the crisis on global economic growth rates was much smaller on average than that of the 2008-09 crisis, so it may be more revealing to look at countries' departure from their overall trend during that period. Secondly, for the countries hardest hit by the crisis (the East Asian tigers), the peak to trough drop in growth rates from 1997 to 1998 is, in some cases, quite striking. For example, South Korea dropped from a growth rate of real GDP in 1997 of $4.5 \%$ to a rate of 7.1\% in 1998. De-trended growth rates pick up the dramatic and sudden swings in growth rates particular to periods of financial crisis.

Perhaps unsurprisingly, the model does not perform well when fit to unadjusted 1998 growth rates, as shown in the rightmost panel of the top half of Table 8. Using unadjusted growth rates likely hides the true impact of the 1997 crisis, which had a dampened impact on strongly growing developed economies. When we apply the model to de-trended growth rates, however, the fit of the model improves substantially. In fact, the 
model for de-trended growth rates across crisis periods (appearing in the bottom half of Table 8) shows some significant similarities. Although some coefficient estimates do in some cases differ in magnitude and/or sign, the role of the variables in explaining variation in impact of the crisis remains, with the exception of the current account variable for the 1997 crisis. In particular, a 2-class model best fits either crisis, with the log of pre-crisis income per capita a significant determinant of class membership for both episodes. Precrisis growth in banking credit appears to be a significant and negative predictor of crisis period growth performance across specifications and crisis episodes. This lends support for the robustness of this variable in explaining variation in crisis impact. Status as a commodity exporter and pre-crisis inflation also retain explanatory power, although their signs do change across specifications in some cases. This may result from the differential nature of the crises.

There may be several reasons why the model fitting the 08-09 is not entirely consistent with the 1997 Asian financial crisis, qualitatively speaking. The nature of the crisis itself differed in the key aspect that it originated in, and affected, emerging market economies more severely than developed economies, in contrast to the 2008-09 crisis which centered on the developed world. Of course, the global downturn was also much less severe and shorter in length than the 08-09 crisis. Therefore, the fundamental nature of each crisis differs. This fact highlights the difficulty in creating simple linear models to predict financial crises, as they are unlikely to model these complex relationships. The results remain interesting however, as the included variables do seem to retain some explanatory power across time periods, even if their qualitative interpretation changes across episodes in some cases. Similarly, the model identifies 2 classes for each period, where pre-crisis income helps in predicting class membership. It remains an open question if finding additional sources of the heterogeneity in relationships across episodes may improve the performance of early warning models, which provides an area for future work. What is provided here is evidence that simple linear models fail to capture the complex nature of financial crises. When models that incorporate heterogeneous relationships are used, sets of indicators appear to be robust across crisis episodes.

\section{Conclusion}

Rose and Spiegel (2009a,b) and Rose and Spiegel (2010) use a comprehensive set of financial and macroeconomic indicators to demonstrate that almost no indicators are empirically robust in terms of predicting crisis incidence, which would be a necessary first step in building an empirical EWM. We find that this result is robust to model uncertainty using Bayesian model averaging, as no individual indicators are statistically significant or have a high posterior probability of inclusion in the model. 
However, when using a nonlinear method such as latent class models, our results appear quite different. We provide evidence that the sample can generally be split into two 'classes', which are influenced by countries' initial income. The parameters of indicator variables differ between classes in magnitude, sign, and even in inclusion in the model of the separate classes. This reveals a more complex crisis-response framework than assumed in previous EWM literature. We also provide evidence that several indicators are useful and robust in explaining variations in impact from the 2008-09 crisis, including the growth in banking credit from 2000-06, inflation, the degree of credit market regulation, status as a major commodity exporter, and several financial and institutional variables.

Our results also appear to be robust to other crises using alternative data. In particular, we applied the model to data from the 1997 financial crisis period. We find that while the results are not entirely consistent across episodes, due to the changing qualitative interpretation of some variables, there is evidence of similar heterogeneity persisting across periods, where the chosen set of indicators explain variation in the impact of the crisis. A particularly robust indicator includes the pre-crisis growth in banking credit, which performs well across specifications and sample period. A 2-class model best fits both the 2008-09 crisis as well as the 1997 Asian crisis, where the 2 classes are differentiated by their mean income levels as well as the extent of the real damage to their economies. 


\section{References}

1. Bekaert, G., M. Ehrmann, M. Fratzscher, and A. Mehl (2011). "Global Crises and Equity Market Contagion", National Bureau of Economic Research, Inc, NBER Working Papers: 17121.

2. Beltratti, A. and R.M. Stulz (2009). "Why Did Some Banks Perform Better During the Credit Crisis? A Cross-Country Study of the Impact of Governance and Regulation", National Bureau of Economic Research, Inc, NBER Working Papers: 15180.

3. Berkmen, S.P., G. Gelos, R. Rennhack, and J.P. Walsh (2012). "The Global Financial Crisis: Explaining Cross-Country Differences in the Output Impact", Journal of International Money and Finance, 2012. 31(1), p. 42-59.

4. Blanchard, O.J., M. Das, and H. Faruqee (2010). "The Initial Impact of the Crisis on Emerging Market Countries", Brookings on Economic Activity, p. 263-307.

5. Brock, W.A. and S.N. Durlauf (2001). "Growth Empirics and Reality", World Bank Economic Review, 15(2), p. 229-272.

6. Burnham, K.P. and D.R. Anderson (2004). "Multimodel Inference: Understanding AIC and BIC in Model Selection", Sociological Methods \& Research, 33(2), p. 261-304.

7. Claessens, S., G. Dell'Ariccia, D. Igan, and L. Laeven (2010). "Lessons and Policy Implications from the Global Financial Crisis", Working paper, International Monetary Fund.

8. Ehrmann, M., M. Fratzscher, and A. Mehl (2009). "What Has Made the Financial Crisis Truly Global?", Unpublished Working Paper, European Central Bank.

9. Eichengreen, B., A. Mody, M. Nedeljkovic, and L. Sarno (2012). "How the Subprime Crisis Went Global: Evidence from Bank Credit Default Swap Spreads", Journal of International Money and Finance, 31(5), p. 1299-1318.

10. Fernandez, C., E. Ley, and M.F.J. Steel (2001). "Model Uncertainty in Cross-Country Growth Regressions", Journal of Applied Econometrics, 16(5), p. 563-576.

11. Frankel, J. and G. Saravelos (2011). "Can Leading Indicators Assess Country Vulnerability? Evidence from the 2008-09 Global Financial Crisis", Harvard University, John F. Kennedy School of Government, Working Paper Series.

12. Giannone, D., M. Lenza, and L. Reichlin (2011). "Market Freedom and the Global Recession", IMF Economic Review, 59(1), p. 111-135. 
13. Lane, P.R. and G.M. Milesi-Ferretti (2011). "The Cross-Country Incidence of the Global Crisis", IMF Economic Review, 59(1), p. 77-110.

14. Ley, E. and M.F.J. Steel (2009). "On the Effect of Prior Assumptions in Bayesian Model Averaging with Applications to Growth Regression", Journal of Applied Econometrics, 24(4), p. 651-674.

15. Rose, A.K. and M. Spiegel (2010). "Cross-Country Causes and Consequences of the Crisis: An Update", C.E.P.R. Discussion Papers, CEPR Discussion Papers: 7901.

16. Rose, A.K. and M.M. Spiegel (2009a). "Cross-country causes and consequences of the 2008 crisis: early warning", Federal Reserve Bank of San Francisco, Working Paper Series: 2009-17.

17. Rose, A.K. and M.M. Spiegel (2009b), "Cross-country causes and consequences of the 2008 crisis: international linkages and American exposure", Federal Reserve Bank of San Francisco, Working Paper Series: 2009-18.

18. Shoham, A. and J. Pelzman (2011). "A Review of the Crises", Global Economy Journal, 11(2), p. 1-20.

19. Vermunt, J.K. and J. Magidson (2005). Latent Gold 4.0 User's Guide. Belmont, MA: Statistical Innovations, Inc.

20. Vermunt, J.K. and J. Magidson (2005). Latent Gold 4.0 Technical Manual. Belmont, MA: Statistical Innovations, Inc. 
Table 1 - Variable Description

Category 1 - Size and Income

Category 6 - Macroeconomic Policies

Log of Real GDP per Capita, 2006

Log of Total Population, 2006

Category 2 - Financial Policies

Bank Ownership (share of bank deposits held in privately owned banks), 200

Foreign Bank Competition (denial rate of foreign bank license applications), 2006

Credit Market Regulation

Overall Capital Stringency, 2003

Ability to Take Prompt Corrective Action, 2003

Capital Regulatory Index, 2003

Official Supervisory Power, 2003

Restructuring Power, 2003

Power to Declare Insolvency, 2003

Category 3 - Financial Conditions

Private Sector Domestic Credit (share of GDP), 2006

Change in Banking Credit\% GDP 2000-2006

Change in Private Credit\% GDP 2000-2006

Domestic Bank Credit \% GDP 2006

Domestic Private Credit \% GDP 2006

Bank Liquid Reserves (share of assets)

Bank Nonperforming Loan Ratio

Bank Capital (share of assets)

Bank Claims (share of assets), 2006

Category 4 - Asset Price Appreciation

Percentage Change in Real Estate Prices (2000-06)

Market Capitalization (share of GDP)

Stocks Total Value Traded/GDP

Stock Market Growth

Category 5 - International Imbalances

Net External Position (\% GDP)

Current Account (\%GDP)

Average Current Account/GDP Ratio 2004-2007

Fixed Exchange Rate Regime

External Debt Stocks \% GNI 2006

External Short Term Debt/GDP - extdebtgdp

Short Term Debt/Total External Debt

Total Resevers(-gold)/GDP

Real Effective Exchange Rate Change 2000-2006

Currency Union (dummy=1 if member of)

Inflation Targeter (dummy)

M2/GDP

$\mathrm{M} 3 / \mathrm{GDP}$

Total Debt (\%GDP)

Debt Service Burden (\%GDP)

CPI Inflation

Moody's Sovereign LT Rating 2006

Net Government Borrowing/Lending (\%GDP)

Net Government Debt (\%GDP)

Regulation of Credit/Labor/Business

GDP Growth, 2006

Category 7 - Institutional Factors

EFW Index of Credit/Labor/Business Regulation

Polity Index, 2006

Control of Corruption, 2002

Regulatory Quality

Rule of Law

Political Rights

Civil Liberty, 2005

Government Size

Security of Property Rights

Advanced Economy

Voice \& Accountability Index

Overall Economic Freedom Index

Government Effectiveness Index

Labor Market Regulations

Business Regulations

Sound Money Access

Not a Financial Center

Share of Manufacturing in GDP

Category 8 - Geography

Log of Latitude

Regional Dummy

Commodity Exporter Dummy

Category 9 - Financial and Trade Linkages

US TIC Assets/GDP

US TIC Equity/GDP

US TIC Long Debt/GDP

US TIC Debt/GDP

US TIC Treasuries/GDP

Trade with US (\% total trade)

Average Growth in Trading Partners' GDP 2005-2007

Average Growth in Trading Partners' GDP 2008-2008 
Table 2 - Country List

Europe

\begin{tabular}{|l|}
\hline+2 \\
\hline \\
\hline \\
\hline
\end{tabular}

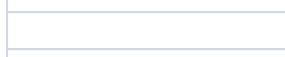

\begin{tabular}{|r|r|r|}
\hline \\
\hline
\end{tabular}

\begin{tabular}{|l|}
\hline+2 \\
\hline
\end{tabular}

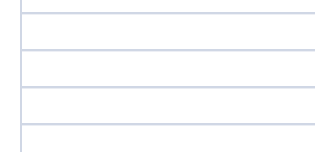

$\mid+2$

\begin{tabular}{|c|c|c|c|c|}
\hline & Central Asia & & Carribean/Island & \\
\hline Albania & & Kazakhstan & & Antigua \& Barbuda \\
\hline Armenia & & Kyrgyz Rep. & & Bahamas \\
\hline Austria & & Sri Lanka & & Barbados \\
\hline Belarus & & Turkey & & Bermuda \\
\hline Belgium & & Turkmenistan & & Cuba \\
\hline Bulgaria & Middle East/North & Africa & & Dominican Rep. \\
\hline Croatia & & Algeria & & Haiti \\
\hline Cyprus & & Bahrain & & Jamaica \\
\hline Czech Rep. & & Egypt & & Netherlands Antilles \\
\hline Denmark & & Iran & & Puerto Rico \\
\hline Estonia & & Israel & & St. Kitts and Nevis \\
\hline Finland & & Kuwait & & Trinidad and Tobago \\
\hline France & & Lebanon & South America & \\
\hline Georgia & & Libya & & Argentina \\
\hline Germany & & Morocco & & Brazil \\
\hline Greece & & Oman & & Chile \\
\hline Hungary & & Qatar & & Colombia \\
\hline Iceland & & Saudi Arabia & & Costa Rica \\
\hline Italy & & Tunisia & & Ecuador \\
\hline Latvia & & United Arab Emirates & & El Salvador \\
\hline Lithuania & Sub-Saharan Africa & & & Panama \\
\hline Luxembourg & & Botswana & & Paraguay \\
\hline Macedonia & & Eq. Guinea & & Peru \\
\hline Malta & & Gabon & & Uruguay \\
\hline Netherlands & & Guyana & & Venezuela \\
\hline Norway & & Mauritius & East Asia & \\
\hline Poland & & Namibia & & Brunei Darussalem \\
\hline Portugal & & Seychelles & & China \\
\hline Romania & & South Africa & & Hong Kong \\
\hline Russia & & Swaziland & & Indonesia \\
\hline Slovakia & Pacific & & & Japan \\
\hline Slovenia & & Australia & & Korea \\
\hline Spain & & New Zealand & & Macao \\
\hline Sweden & & Papua New Guinea & & Malaysia \\
\hline Switzerland & North America & & & Singapore \\
\hline UK & & Canada & & Taiwan \\
\hline \multirow[t]{2}{*}{ Ukraine } & & Mexico & & Thailand \\
\hline & & United States & & \\
\hline
\end{tabular}




\begin{tabular}{|c|c|c|c|}
\hline Variable & PIP & Post Mean & Post Std. Dev. \\
\hline Credit Market Regulation & 0.413 & -1.206 & 1.587 \\
\hline Growth in Banking Credit & 0.379 & -0.037 & 0.053 \\
\hline Bank Claim/Deposit Ratio & 0.289 & -1.634 & 2.830 \\
\hline Log of Latitude & 0.234 & -0.583 & 1.173 \\
\hline Growth in Private Credit & 0.206 & -2.698 & 5.914 \\
\hline Foreign Banking Competition & 0.203 & -0.317 & 0.702 \\
\hline Control of Corruption & 0.164 & 0.957 & 2.539 \\
\hline Moody's 2006 Sovereign Credit Rating & 0.152 & 0.145 & 0.399 \\
\hline Bank Ownership & 0.116 & -0.098 & 0.322 \\
\hline Net Government Borrowing/Lending, \% GDP & 0.091 & 0.037 & 0.137 \\
\hline Regulatory Quality & 0.083 & -0.621 & 2.531 \\
\hline Current Account/GDP & 0.070 & 1.379 & 6.301 \\
\hline Polity 2 Index & 0.065 & -0.023 & 0.106 \\
\hline Manufacturing Share & 0.065 & -0.014 & 0.068 \\
\hline Commondity Exporter & 0.055 & 0.157 & 0.855 \\
\hline Reserves/GDP & 0.054 & -0.006 & 0.031 \\
\hline Advanced Economy & 0.048 & -0.173 & 1.038 \\
\hline Rule of Law & 0.047 & 0.129 & 1.089 \\
\hline Log of 2006 GDP per capita & 0.044 & -0.114 & 0.761 \\
\hline Government Effectiveness Index & 0.040 & -0.009 & 1.016 \\
\hline CPI Inflation & 0.039 & -0.014 & 0.104 \\
\hline Trade Share with US & 0.037 & 0.002 & 0.017 \\
\hline Net External Position & 0.036 & -0.092 & 0.729 \\
\hline Bank Capital/Asset Ratio & 0.034 & -0.009 & 0.077 \\
\hline Size of Government & 0.032 & 0.018 & 0.158 \\
\hline Voice and Accountability Index & 0.029 & -0.034 & 0.504 \\
\hline Log of Population & 0.028 & 0.011 & 0.151 \\
\hline Stock Market Capitalization 2003-2006 & 0.028 & 0.025 & 0.259 \\
\hline Liquid Resevers/Assets & 0.027 & -0.001 & 0.025 \\
\hline Bank Nonperforming Loan Ratio & 0.025 & 0.001 & 0.049 \\
\hline Fixed Exchange Rate Regime & 0.025 & -0.025 & 0.350 \\
\hline Mean No. Regressors & 3.1571 & & \\
\hline g-Prior & UIP & & \\
\hline Model Prior & Random & & \\
\hline Corr PMP & 0.9994 & & \\
\hline
\end{tabular}




\begin{tabular}{|c|c|c|c|}
\hline Variable & PIP & $\begin{array}{l}\text { Post } \\
\text { Mean }\end{array}$ & $\begin{array}{c}\text { Post Std. } \\
\text { Dev. }\end{array}$ \\
\hline Bank Claim/Deposit Ratio & 0.553 & -2.314 & 2.630 \\
\hline Control of Corruption & 0.487 & 2.616 & 3.648 \\
\hline Growth in Banking Credit & 0.474 & -0.030 & 0.042 \\
\hline Log of Latitude & 0.437 & -0.842 & 1.253 \\
\hline Credit Market Regulation & 0.410 & -0.681 & 1.313 \\
\hline Reserves/GDP & 0.390 & -0.048 & 0.081 \\
\hline Moody's 2006 Sovereign Credit Rating & 0.377 & 0.233 & 0.440 \\
\hline Advanced Economy & 0.366 & -1.580 & 2.858 \\
\hline Foreign Banking Competition & 0.361 & -0.335 & 0.641 \\
\hline Regulatory Quality & 0.348 & -1.797 & 3.599 \\
\hline Net Government Borrowing/Lending, \% GDP & 0.335 & 0.100 & 0.198 \\
\hline Growth in Private Credit & 0.327 & -2.187 & 4.801 \\
\hline Bank Ownership & 0.310 & -0.152 & 0.378 \\
\hline Polity 2 Index & 0.287 & -0.075 & 0.185 \\
\hline Manufacturing Share & 0.263 & -0.033 & 0.100 \\
\hline Net External Position & 0.256 & -0.529 & 1.621 \\
\hline Rule of Law & 0.255 & 0.339 & 2.387 \\
\hline Current Account/GDP & 0.254 & 1.779 & 9.142 \\
\hline Bank Capital/Asset Ratio & 0.251 & -0.065 & 0.189 \\
\hline Stock Market Capitalization 2003-2006 & 0.245 & 0.248 & 0.801 \\
\hline Government Effectiveness Index & 0.243 & 0.094 & 2.220 \\
\hline CPI Inflation & 0.240 & -0.051 & 0.213 \\
\hline Log of 2006 GDP per capita & 0.232 & -0.285 & 1.404 \\
\hline Trade Share with US & 0.230 & -0.004 & 0.036 \\
\hline Size of Government & 0.223 & 0.069 & 0.322 \\
\hline Log of Population & 0.222 & 0.096 & 0.431 \\
\hline Voice and Accountability Index & 0.220 & -0.042 & 1.493 \\
\hline Commondity Exporter & 0.217 & 0.082 & 1.282 \\
\hline Fixed Exchange Rate Regime & 0.213 & -0.169 & 0.979 \\
\hline Liquid Resevers/Assets & 0.212 & -0.008 & 0.069 \\
\hline Bank Nonperforming Loan Ratio & 0.204 & -0.014 & 0.157 \\
\hline
\end{tabular}

Mean No. Regressors

9.4411

g-Prior

Model Prior

Hyper ( $a=2.03704)$

Corr PMP

Random

0.9924 


\begin{tabular}{|c|c|c|c|c|c|c|c|}
\hline Variable & BIC selection & CAIC selection & 1 class sign. & 2 class sign. & 3 class sign. & ly included (covariate) & ly included (regressor) \\
\hline \multirow[t]{4}{*}{ Advanced Economy (dummy) } & 1 Class & 1 Class & sign. & sign. - 1 Class & sign. - 2 Class & no & no \\
\hline & 1 Class & 1 Class & sign. & sign. & sign. - 2 Class & yes & no \\
\hline & 1 Class & 1 Class & sign. & sign. - 1 Class & sign. - 2 Class & no & yes \\
\hline & 1 Class & 1 Class & sign. & sign. - 1 Class & $\sim$ sign. & yes & yes \\
\hline \multirow[t]{2}{*}{ US TIC Short Debt/GDP } & 1 Class & 1 Class & insign. & insign. & sign. - 1 Class & no & no \\
\hline & 2 Class & 2 Class & insign. & insign. & sign. - 1 Class & yes & no \\
\hline \multirow[t]{2}{*}{ US TIC Long Debt/GDP } & 1 Class & 1 Class & insign. & insign. & sign. - 1 Class & no & no \\
\hline & 2 Class & 1 Class & insign. & sign. - $1 \mathrm{Class}$ & sign. - $1 \mathrm{Class}$ & $s$ yes & no \\
\hline \multirow[t]{2}{*}{ US TIC Equity/GDP } & 1 Class & 1 Class & insign. & insign. & sign. - 1 Class & no & no \\
\hline & 2 Class & 1 Class & insign. & insign. & insign. & yes & no \\
\hline \multirow[t]{2}{*}{ US TIC Debt/GDP } & 1 Class & 1 Class & insign. & sign. - 1 Class & sign. - 2 Class & no & no \\
\hline & 3 Class & 2 Class & insign. & sign. - 1 Class & sign. - 2 Class & yes & no \\
\hline \multirow[t]{2}{*}{ US TIC Assets/GDP } & 1 Class & 1 Class & insign. & sign. - 2 Class & sign. - $1 \mathrm{Class}$ & s no & no \\
\hline & 2 Class & 2 Class & insign. & insign. & sign. - 1 Class & yes & no \\
\hline \multirow[t]{2}{*}{ US TIC Treasuries/GDP } & 1 Class & 1 Class & insign. & insign. & sign. - 2 Class & no & no \\
\hline & 1 Class & 1 Class & insign. & sign. - 1 Class & sign. - 1 Class & yes & no \\
\hline \multirow[t]{4}{*}{ Bank Ownership 2006} & 1 Class & 1 Class & sign. & sign. & sign. - 2 Class & no & no \\
\hline & 2 Class & 1 Class & sign. & sign. - 1 Class & sign. - 2 Class & yes & no \\
\hline & 1 Class & 1 Class & sign. & sign. - 1 Class & sign. & no & yes \\
\hline & 1 Class & 1 Class & sign. & sign. - $1 \mathrm{Class}$ & sign. & yes & yes \\
\hline \multirow[t]{4}{*}{ Bank Capital/Asset Ratio 2006} & 1 Class & 1 Class & insign. & insign. & sign. - 1 Class & no & no \\
\hline & 2 Class & 2 Class & insign. & sign. - 1 Class & sign. & yes & no \\
\hline & 1 Class & 1 Class & insign. & sign. & sign. - 2 Class & no & yes \\
\hline & 1 Class & 1 Class & insign. & sign. & sign. & yes & yes \\
\hline \multirow[t]{4}{*}{ Bank Nonperforming Loan Ratio 2006} & 1 Class & 1 Class & sign. & sign. - 1 Class & sign. & no & no \\
\hline & 2 Class & 1 Class & sign. & sign. & sign. - 2 Class & yes & no \\
\hline & 1 Class & 1 Class & sign. & sign. & sign. & no & yes \\
\hline & 1 Class & 1 Class & sign. & sign. & sign. & yes & yes \\
\hline \multirow[t]{2}{*}{ Business Regulations 2006} & 1 Class & 1 Class & sign. & sign. - 1 Class & sign. - 2 Class & no & no \\
\hline & $1 \mathrm{Class}$ & $1 \mathrm{Class}$ & sign. & sign. - 1 Class & insign. & yes & no \\
\hline \multirow[t]{2}{*}{ Current Account \% GDP 2006} & 1 Class & 1 Class & sign. & sign. & sign. & no & no \\
\hline & 2 Class & 2 Class & sign. & sign. & sign. & yes & no \\
\hline \multirow[t]{4}{*}{ Current Account/GDP 2007} & 1 Class & 1 Class & sign. & sign. & sign. & no & no \\
\hline & 2 Class & 2 Class & sign. & sign. & sign. & yes & no \\
\hline & 1 Class & 1 Class & sign. & sign. & sign. & no & yes \\
\hline & 1 Class & 1 Class & sign. & sign. & sign. & yes & yes \\
\hline \multirow[t]{2}{*}{ Average Current Account/GDP ratio 2004-2007 } & 1 Class & 1 Class & sign. & sign. & sign. & no & no \\
\hline & 2 Class & 2 Class & sign. & sign. & sign. & yes & no \\
\hline \multirow[t]{2}{*}{ Capital Regulatory Index 2003} & 1 Class & 1 Class & insign. & sign. - 1 Class & sign. - 2 Class & no & no \\
\hline & 1 Class & 1 Class & insign. & insign. & sign. - 2 Class & yes & no \\
\hline \multirow[t]{4}{*}{ Civil Liberties Index 2005} & 1 Class & 1 Class & sign. & sign. & sign. & no & no \\
\hline & 1 Class & 1 Class & sign. & sign. & sign. & yes & no \\
\hline & 1 Class & 1 Class & sign. & sign. & sign. - 2 Class & no & yes \\
\hline & 1 Class & 1 Class & sign. & sign. & sign. - 2 Class & yes & yes \\
\hline \multirow[t]{4}{*}{ Bank Claim/Deposit Ratio 2006} & 1 Class & 1 Class & sign. & sign. - 1 Class & sign. - 2 Class & no & no \\
\hline & 1 Class & 1 Class & sign. & sign. - $1 \mathrm{Class}$ & sign. - 2 Class & yes & no \\
\hline & 1 Class & 1 Class & sign. & sign. - $1 \mathrm{Class}$ & sign. - 2 Class & no & yes \\
\hline & 1 Class & 1 Class & sign. & sign. - $1 \mathrm{Class}$ & sign. - 2 Class & yes & yes \\
\hline
\end{tabular}




\begin{tabular}{|c|c|c|c|c|c|c|c|}
\hline Variable & BIC selection & CAIC selection & 1 class sign. & 2 class sign. & 3 class sign. & ly included (covariate) & ly included (regressor) \\
\hline \multirow[t]{4}{*}{ Big Commodity Exporter } & 1 Class & 1 Class & sign. & sign. - 1 Class & sign. & no & no \\
\hline & 2 Class & 1 Class & sign. & sign. & sign. - 2 Class & yes & no \\
\hline & 1 Class & 1 Class & sign. & sign. - 1 Class & sign. & no & yes \\
\hline & 1 Class & 1 Class & sign. & sign. - 1 Class & sign. & yes & yes \\
\hline \multirow[t]{2}{*}{ Control of Corruption Index 2002} & 1 Class & 1 Class & sign. & sign. - 1 Class & sign. - 2 Class & no & no \\
\hline & 1 Class & 1 Class & sign. & sign. - 1 Class & sign. - 1 Class & yes & no \\
\hline \multirow[t]{4}{*}{ CPI Inflation 2006} & 1 Class & 1 Class & sign. & sign. - 1 Class & sign. - 2 Class & no & no \\
\hline & 2 Class & 1 Class & sign. & sign. - 1 Class & sign. - 1 Class & yes & no \\
\hline & 1 Class & 1 Class & insign. & insign. & sign. - 2 Class & no & yes \\
\hline & 2 Class & 1 Class & insign. & sign. - 1 Class & sign. - 2 Class & yes & yes \\
\hline \multirow[t]{4}{*}{ Credit Market Regulations 2006} & 1 Class & 1 Class & sign. & sign. - 2 Class & sign. & no & no \\
\hline & 1 Class & 1 Class & sign. & sign. - 1 Class & sign. - 2 Class & yes & no \\
\hline & 1 Class & 1 Class & sign. & sign. - 1 Class & sign. - 2 Class & no & yes \\
\hline & 1 Class & 1 Class & sign. & sign. - 1 Class & sign. - 2 Class & yes & yes \\
\hline \multirow[t]{4}{*}{ Change in Banking Credit\% GDP 2000-2006 } & 1 Class & 1 Class & sign. & sign. & sign. - 2 Class & no & no \\
\hline & 1 Class & $1 \mathrm{Class}$ & sign. & sign. & sign. - 2 Class & yes & no \\
\hline & 1 Class & 1 Class & sign. & sign. & sign. & no & yes \\
\hline & 1 Class & 1 Class & sign. & sign. - 1 Class & sign. & yes & yes \\
\hline \multirow[t]{2}{*}{ Debt Service Burden (\%GDP) } & 1 Class & 1 Class & insign. & sign. - 1 Class & sign. & no & no \\
\hline & 1 Class & 1 Class & insign. & sign. - 1 Class & sign. & yes & no \\
\hline \multirow[t]{2}{*}{ Power to Declare Insolvency 2003} & 1 Class & 1 Class & insign. & insign. & sign. - 1 Class & no & no \\
\hline & 1 Class & 1 Class & insign. & insign. & insign. & yes & no \\
\hline \multirow[t]{4}{*}{ Domestic Bank Credit \% GDP 2006} & 1 Class & 1 Class & sign. & sign. - 1 Class & sign. & no & no \\
\hline & 1 Class & 1 Class & sign. & sign. - 1 Class & sign. - 2 Class & yes & no \\
\hline & 1 Class & 1 Class & insign. & sign. & sign. - 2 Class & no & yes \\
\hline & 1 Class & 1 Class & insign. & sign. & sign. & yes & yes \\
\hline \multirow[t]{4}{*}{ Domestic Private Credit \% GDP 2006} & 1 Class & 1 Class & sign. & sign. & sign. & no & no \\
\hline & 1 Class & 1 Class & sign. & insign. & sign. - 2 Class & yes & no \\
\hline & 1 Class & 1 Class & insign. & sign. - 1 Class & sign. - 2 Class & no & yes \\
\hline & 1 Class & 1 Class & insign. & sign. - 1 Class & sign. - 2 Class & yes & yes \\
\hline \multirow[t]{4}{*}{ Change in Private Credit\% GDP 2000-2006 } & 1 Class & 1 Class & sign. & sign. & sign. - 2 Class & no & no \\
\hline & 1 Class & 1 Class & sign. & sign. - 1 Class & sign. - 1 Class & yes & no \\
\hline & 1 Class & 1 Class & sign. & sign. - 1 Class & sign. - 2 Class & no & yes \\
\hline & 1 Class & 1 Class & sign. & sign. - 1 Class & sign. - 2 Class & yes & yes \\
\hline \multirow[t]{2}{*}{ East Asia/Pacific Dummy } & 1 Class & 1 Class & sign. & sign. & sign. - 1 Class & no & no \\
\hline & 2 Class & & sign. & sign. & sign. - 2 Class & yes & no \\
\hline \multirow[t]{2}{*}{ EFW Summa ry 2006} & 1 Class & 1 Class & sign. & sign. - 1 Class & sign. - 1 Class & no & no \\
\hline & 2 Class & 1 Class & sign. & insign. & sign. - 1 Class & yes & no \\
\hline \multirow[t]{2}{*}{ Europe/Central Asia Dummy } & 1 Class & 1 Class & sign. & sign. - 1 Class & sign. - 1 Class & no & no \\
\hline & 2 Class & & sign. & sign. & sign. - 1 Class & yes & no \\
\hline \multirow[t]{4}{*}{ External Debt Stocks \% GNI 2006} & 1 Class & 1 Class & insign. & sign. - 1 Class & sign. - 2 Class & no & no \\
\hline & 1 Class & 1 Class & insign. & sign. - 1 Class & sign. - 2 Class & yes & no \\
\hline & 1 Class & 1 Class & sign. & sign. & sign. & no & yes \\
\hline & 1 Class & 1 Class & sign. & sign. - 1 Class & sign. - 2 Class & yes & yes \\
\hline \multirow[t]{2}{*}{ External Debt (\%GDP) } & 1 Class & 1 Class & sign. & sign. - 1 Class & sign. - 2 Class & no & no \\
\hline & 1 Class & 1 Class & sign. & sign. - 1 Class & sign. - 2 Class & yes & no \\
\hline \multirow[t]{4}{*}{ External Short Term Debt/GDP } & 1 Class & 1 Class & sign. & sign. & sign. - 2 Class & no & no \\
\hline & 1 Class & 1 Class & sign. & sign. & sign. & yes & no \\
\hline & 1 Class & 1 Class & sign. & sign. & sign. & no & yes \\
\hline & 1 Class & $1 \mathrm{Class}$ & sign. & sign. & sign. & yes & yes \\
\hline
\end{tabular}




\begin{tabular}{|c|c|c|c|c|c|c|c|}
\hline Variable & BIC selection & CAIC selection & 1 class sign. & 2 class sign. & 3 class sign. & ly included (covariate) & ly included (regressor) \\
\hline \multirow[t]{2}{*}{ Fixed Exchange Rate Regime } & 1 Class & 1 Class & insign. & sign. - 1 Class & insign. & no & no \\
\hline & 2 Class & 1 Class & insign. & insign. & insign. & yes & no \\
\hline \multirow[t]{4}{*}{ Foreign Bank Competition 2006} & 1 Class & 1 Class & sign. & sign. & sign. - 2 Class & no & no \\
\hline & 2 Class & 1 Class & sign. & sign. - 1 Class & sign. - 2 Class & yes & no \\
\hline & 1 Class & 1 Class & sign. & sign. - 1 Class & sign. - 2 Class & no & yes \\
\hline & 1 Class & 1 Class & sign. & sign. - 1 Class & sign. - 1 Class & yes & yes \\
\hline \multirow[t]{4}{*}{ Government Effectiveness Index 2002} & 1 Class & 1 Class & sign. & sign. - 1 Class & sign. - 2 Class & no & no \\
\hline & 1 Class & 1 Class & sign. & sign. - 1 Class & sign. & yes & no \\
\hline & 1 Class & 1 Class & sign. & sign. & sign. - 2 Class & no & yes \\
\hline & 1 Class & 1 Class & sign. & sign. - 1 Class & sign. - 2 Class & yes & yes \\
\hline \multirow[t]{2}{*}{ GDP growth 2006} & 2 Class & 2 Class & insign. & sign. - 1 Class & sign. - 2 Class & no & no \\
\hline & 3 Class & 3 Class & insign. & sign. - 1 Class & sign. - 2 Class & yes & no \\
\hline \multirow[t]{4}{*}{ Real Housing Price Appreciation 2000-2006 } & 2 Class & 1 Class & sign. & sign. & sign. & no & no \\
\hline & 2 Class & 1 Class & sign. & sign. - 1 Class & sign. & yes & no \\
\hline & 2 Class & 1 Class & sign. & sign. - 1 Class & sign. - 2 Class & no & yes \\
\hline & 1 Class & 1 Class & sign. & sign. - 1 Class & sign. - 2 Class & yes & yes \\
\hline \multirow[t]{2}{*}{ Inflation Targeter } & 1 Class & 1 Class & insign. & insign. & sign. - 1 Class & no & no \\
\hline & 2 Class & 1 Class & insign. & insign. & sign. - 1 Class & yes & no \\
\hline \multirow[t]{2}{*}{ Labor Market Regulations 2006} & 1 Class & 1 Class & insign. & sign. - 1 Class & sign. - 1 Class & no & no \\
\hline & 2 Class & 1 Class & insign. & insign. & sign. - 1 Class & yes & no \\
\hline \multirow[t]{2}{*}{ Latin American/Carribean Dummy } & 1 Class & 1 Class & insign. & insign. & insign. & no & no \\
\hline & 1 Class & & insign. & insign. & sign. - 1 Class & yes & no \\
\hline \multirow[t]{4}{*}{ Bank Liquid Reserves/Assets 2006} & 1 Class & 1 Class & sign. & sign. - 1 Class & sign. - 2 Class & no & no \\
\hline & 1 Class & 1 Class & sign. & sign. - 1 Class & sign. - 2 Class & yes & no \\
\hline & 1 Class & 1 Class & sign. & sign. - 1 Class & sign. - 2 Class & no & yes \\
\hline & 1 Class & 1 Class & sign. & sign. - 1 Class & sign. - 2 Class & yes & yes \\
\hline \multirow[t]{2}{*}{ Log of Lattitude } & 1 Class & 1 Class & sign. & sign. & sign. - 2 Class & no & no \\
\hline & 1 Class & 1 Class & sign. & sign. & sign. - 1 Class & yes & no \\
\hline \multirow[t]{2}{*}{ Log of 2006 Population } & 1 Class & 1 Class & insign. & sign. & sign. - 2 Class & no & no \\
\hline & 2 Class & 1 Class & insign. & insign. & sign. - 1 Class & yes & no \\
\hline \multirow[t]{2}{*}{ Log of 2006 GDP per Capita } & 1 Class & 1 Class & sign. & sign. - 1 Class & sign. - 2 Class & no & no \\
\hline & & & sign. & sign. - 1 Class & sign. - 1 Class & yes & no \\
\hline \multirow[t]{2}{*}{ M2/GDP 2006} & 1 Class & 1 Class & insign. & sign. & sign. - 1 Class & no & no \\
\hline & 1 Class & 1 Class & insign. & sign. - 1 Class & sign. - 2 Class & yes & no \\
\hline \multirow[t]{2}{*}{ M3/GDP 2006} & 1 Class & 1 Class & insign. & sign. - 2 Class & sign. - 1 Class & no & no \\
\hline & 1 Class & 1 Class & insign. & sign. - 1 Class & sign. - 2 Class & yes & no \\
\hline \multirow[t]{4}{*}{ Share of Manufacturing in GDP } & 1 Class & 1 Class & insign. & sign. & sign. - 1 Class & no & no \\
\hline & 1 Class & 1 Class & insign. & insign. & sign. - 1 Class & yes & no \\
\hline & 1 Class & 1 Class & 〜sign. & insign. & sign. & no & yes \\
\hline & 1 Class & 1 Class & sign. & sign. - 1 Class & sign. - 2 Class & yes & yes \\
\hline \multirow[t]{2}{*}{ Middle East/North Africa dummy } & 1 Class & 1 Class & sign. & sign. & sign. & no & no \\
\hline & 2 Class & & sign. & sign. & sign. & yes & no \\
\hline \multirow[t]{4}{*}{ Market Capitalization/GDP 2003-2006 } & 1 Class & 1 Class & insign. & sign. & sign. - 1 Class & no & no \\
\hline & 2 Class & 2 Class & rinsign. & insign. & $\sim_{\text {sign. }-2 \text { Class }}$ & syes & no \\
\hline & 1 Class & 1 Class & insign. & sign. & sign. - 2 Class & no & yes \\
\hline & 1 Class & 1 Class & insign. & insign. & sign. - 2 Class & yes & yes \\
\hline \multirow[t]{4}{*}{ Moody Sovereign LT For Rating 2006} & 1 Class & 1 Class & sign. & sign. - 1 Class & sign. -2 Class & no & no \\
\hline & 1 Class & 1 Class & sign. & insign. & $\sim$ sign. -2 Class & 5 yes & no \\
\hline & 1 Class & 1 Class & insign. & sign. - 1 Class & sign. - 2 Class & no & yes \\
\hline & 1 Class & 1 Class & insign. & sign. - 1 Class & sign. - 2 Class & yes & yes \\
\hline
\end{tabular}


Table 5.4 - Bivariate LCM Regression Results

\begin{tabular}{|c|c|c|c|c|c|c|c|}
\hline Variable & BIC selection & CAIC selection & 1 class sign. & 2 class sign. & 3 class sign. & ly included (covariate) & ly included (regressor) \\
\hline \multirow[t]{4}{*}{ Net Government Borrowing/Lending (\%GDP) 2006} & 1 Class & 1 Class & sign. & sign. - 1 Class & sign. -1 Class & no & no \\
\hline & 2 Class & 2 Class & sign. & sign. - 1 Class & sign. - 1 Class & yes & no \\
\hline & 1 Class & 1 Class & sign. & sign. - 1 Class & sign. - 2 Class & no & yes \\
\hline & 1 Class & 1 Class & sign. & sign. - 1 Class & sign. - 2 Class & yes & yes \\
\hline \multirow[t]{4}{*}{ Net Government Debt (\%GDP) } & 1 Class & 1 Class & insign. & sign. - 1 Class & sign. - 2 Class & no & no \\
\hline & 2 Class & 1 Class & insign. & sign. - 1 Class & sign. - 1 Class & yes & no \\
\hline & 1 Class & 1 Class & insign. & sign. - 1 Class & sign. - 2 Class & no & yes \\
\hline & 1 Class & 1 Class & insign. & sign. - 1 Class & sign. - 2 Class & yes & yes \\
\hline \multirow[t]{2}{*}{ Net External Position \% GDP - 2004} & 1 Class & 1 Class & insign. & sign. - 1 Class & sign. - 1 Class & no & no \\
\hline & 1 Class & 1 Class & insign. & sign. & sign. - 2 Class & yes & no \\
\hline \multirow[t]{2}{*}{ Not A Financial Center Dummy } & 1 Class & 1 Class & insign. & insign. & insign. & no & no \\
\hline & 1 Class & 1 Class & insign. & insign. & insign. & yes & no \\
\hline \multirow[t]{2}{*}{ Official Supervis ory Power 2003} & 1 Class & 1 Class & insign. & insign. & insign. & no & no \\
\hline & 1 Class & 1 Class & insign. & insign. & insign. & yes & no \\
\hline \multirow[t]{2}{*}{ Overall Capital Stringency 2003} & 1 Class & 1 Class & insign. & sign. - 2 Class & sign. & no & no \\
\hline & 1 Class & 1 Class & insign. & insign. & sign. - 2 Class & yes & no \\
\hline \multirow[t]{4}{*}{ Polity Index } & 1 Class & 1 Class & sign. & sign. & sign. & no & no \\
\hline & 1 Class & 1 Class & sign. & sign. & sign. - 2 Class & yes & no \\
\hline & 1 Class & 1 Class & sign. & sign. & sign. - 2 Class & no & yes \\
\hline & 1 Class & 1 Class & sign. & sign. & sign. - 2 Class & yes & yes \\
\hline \multirow[t]{2}{*}{ Political Rights Index 2005} & 1 Class & 1 Class & sign. & sign. & sign. & no & no \\
\hline & 1 Class & 1 Class & sign. & sign. & sign. - 2 Class & yes & no \\
\hline \multirow[t]{2}{*}{ Private Credit by Deposit Money Banks } & 1 Class & 1 Class & sign. & sign. - 1 Class & sign. - 1 Class & no & no \\
\hline & 1 Class & 1 Class & sign. & sign. - 1 Class & sign. - 2 Class & yes & no \\
\hline \multirow[t]{2}{*}{ Prompt Corrective Action 2003} & 1 Class & 1 Class & insign. & insign. & sign. - 1 Class & no & no \\
\hline & 1 Class & 1 Class & insign. & insign. & insign. & yes & no \\
\hline Property Rights 2006 & 1 Class & 1 Class & sign. & sign. - 1 Class & sign. - 2 Class & no & no \\
\hline & 1 Class & 1 Class & sign. & sign. - 1 Class & sign. & yes & no \\
\hline Real Effective Exchange Rate change 2000-2006 & 1 Class & 1 Class & insign. & sign. - 1 Class & sign. - 2 Class & no & no \\
\hline & 2 Class & 2 Class & insign. & sign. - 1 Class & sign. - 2 Class & yes & no \\
\hline Regulatory Quality Index 2002 & 1 Class & 1 Class & sign. & sign. & sign. - 2 Class & no & no \\
\hline & 1 Class & 1 Class & sign. & sign. & sign. & yes & no \\
\hline & 1 Class & 1 Class & sign. & sign. & sign. - 2 Class & no & yes \\
\hline & & & sign. & sign. - 1 Class & sign. - 2 Class & yes & yes \\
\hline Regulation Credit/Labor/Business 2006 & 1 Class & 1 Class & sign. & sign. & sign. - 2 Class & no & no \\
\hline & 1 Class & 1 Class & sign. & sign. - 1 Class & sign. - 2 Class & yes & no \\
\hline Total Reserves(-gold)/GDP 2006 & 1 Class & 1 Class & sign. & insign. & sign. - 1 Class & no & no \\
\hline & 2 Class & 1 Class & sign. & s sign. - 1 Class & sign. - 2 Class & yes & no \\
\hline & 1 Class & 1 Class & s sign. & insign. & sign. & no & yes \\
\hline & 1 Class & 1 Class & $\sim$ sign. & insign. & sign. & yes & yes \\
\hline Restructure Power & 1 Class & 1 Class & insign. & sign. - 1 Class & sign. - 2 Class & no & no \\
\hline & 2 Class & 1 Class & insign. & insign. & insign. & yes & no \\
\hline Rule of Law 2002 & 1 Class & 1 Class & sign. & sign. - 1 Class & sign. - 2 Class & no & no \\
\hline & 1 Class & 1 Class & sign. & sign. - 1 Class & sign. & yes & no \\
\hline & 1 Class & 1 Class & $\sim$ sign. & sign. & sign. - 1 Class & no & yes \\
\hline & 1 Class & 1 Class & sign. & sign. - 1 Class & sign. - 2 Class & yes & yes \\
\hline Size of Government 2006 & 1 Class & 1 Class & sign. & s sign. - 1 Class & sign. - 1 Class & no & no \\
\hline & 2 Class & 2 Class & sign. & insign. & sign. - 2 Class & yes & no \\
\hline Sound Money Access 2006 & 1 Class & 1 Class & sign. & sign. - 1 Class & sign. - 1 Class & no & no \\
\hline & 2 Class & 1 Class & sign. & insign. & insign. & yes & no \\
\hline Short Term Debt/Total External Debt 2006 & 1 Class & 1 Class & insign. & sign. - 1 Class & sign. & no & no \\
\hline & 1 Class & 1 Class & insign. & sign. - 1 Class & sign. & yes & no \\
\hline Percent Change in Stock Market Values (USD) 2000-2007 & 1 Class & 1 Class & sign. & sign. - 2 Class & sign. & no & no \\
\hline & 2 Class & 2 Class & sign. & insign. & sign. - 1 Class & yes & no \\
\hline Stock Market Total Value Traded/GDP & 1 Class & 1 Class & insign. & sign. & sign. - 2 Class & no & no \\
\hline & 2 Class & 2 Class & insign. & insign. & sign. - 1 Class & yes & no \\
\hline Sub-Saharan Africa Dummy & 1 Class & 1 Class & insign. & insign. & insign. & no & no \\
\hline & 2 Class & & insign. & sign. - 1 Class & sign. - 2 Class & yes & no \\
\hline Trade with USA/Total Trade & 1 Class & 1 Class & insign. & insign. & sign. - 1 Class & no & no \\
\hline & 1 Class & 1 Class & insign. & insign. & sign. - 2 Class & yes & no \\
\hline & 1 Class & 1 Class & insign. & insign. & sign. - 1 Class & no & yes \\
\hline & 1 Class & 1 Class & insign. & insign. & sign. - 1 Class & yes & yes \\
\hline Voice \& Accountability Index 2002 & 1 Class & 1 Class & sign. & sign. & sign. & no & no \\
\hline & 1 Class & 1 Class & sign. & sign. & sign. - 2 Class & yes & no \\
\hline & 2 Class & 1 Class & sign. & sign. & sign. & no & yes \\
\hline & 1 Class & 1 Class & sign. & sign. & sign. - 2 Class & yes & yes \\
\hline Average Growth in Trading Partners' GDP 2005-2007 & 2 Class & 1 Class & insign. & sign. - 1 Class & sign. - 2 Class & no & no \\
\hline & 2 Class & 2 Class & insign. & sign. - 1 Class & sign. - 2 Class & yes & no \\
\hline Average Growth in Trading Partners' GDP 2008-2008 & 2 Class & 2 Class & sign. & sign. - 1 Class & sign. - 1 Class & no & no \\
\hline
\end{tabular}




\begin{tabular}{|c|c|c|c|c|c|c|c|c|c|c|c|c|c|c|c|c|}
\hline \multirow[b]{2}{*}{ Variable } & \multicolumn{2}{|c|}{ Model 1} & \multicolumn{2}{|c|}{ Model 2} & \multicolumn{2}{|c|}{ Model 3} & \multicolumn{2}{|c|}{ Model 4} & \multicolumn{2}{|c|}{ Model 5} & \multicolumn{2}{|c|}{ Model 6} & \multicolumn{2}{|c|}{ Model 7} & \multicolumn{2}{|c|}{ Model 8} \\
\hline & Class 1 & Class 2 & Class 1 & Class 2 & Class 1 & Class 2 & Class 1 & Class 2 & Class 1 & Class 2 & Class 1 & Class 2 & Class 1 & Class 2 & Class 1 & Class 2 \\
\hline Profile & 0.6589 & 0.3411 & 0.6667 & 0.3333 & 0.737 & 0.263 & 0.7309 & 0.2691 & 0.7116 & 0.2884 & 0.7524 & 0.2476 & 0.6856 & 0.3144 & 0.6737 & 0.3263 \\
\hline Obs & 92 & & 85 & & 79 & & 78 & & 67 & & 67 & & 80 & & 80 & \\
\hline Rsq class & 0.5451 & 0.8265 & 0.6176 & 0.9008 & 0.6415 & 0.9504 & 0.5319 & 0.9565 & 0.6419 & 0.9366 & 0.6031 & 0.9848 & 0.669 & 0.9705 & 0.6967 & 0.9683 \\
\hline Rsq Overall & 0.8021 & & 0.8568 & & 0.8716 & & 0.8499 & & 0.8793 & & 0.8633 & & 0.886 & & 0.8929 & \\
\hline Current Account/GDP & $\begin{array}{l}7.0956 \\
(1.7133)\end{array}$ & $\begin{array}{r}58.1518 \\
{ }^{\prime}(6.7223)\end{array}$ & $\begin{array}{l}0 \\
0\end{array}$ & $\begin{array}{r}36.9735 \\
{ }^{\prime}(3.7125)\end{array}$ & $\begin{array}{l}0 \\
0\end{array}$ & $\begin{array}{r}39.125 \\
(2.4047)\end{array}$ & & & & & $\begin{array}{r}8.3791 \\
=(1.9474)\end{array}$ & $\begin{array}{r}8.3791 \\
(1.9474)\end{array}$ & & & & \\
\hline Growth in Banking Credit & $\begin{array}{l}-0.0391 \\
(-3.1779)\end{array}$ & $\begin{array}{l}-0.3345 \\
(-6.464)\end{array}$ & $\begin{array}{l}-0.0464 \\
(-4.4498)\end{array}$ & $\begin{array}{l}-0.3024 \\
(-5.4416)\end{array}$ & $\begin{array}{l}-0.0464 \\
(-4.0907)\end{array}$ & $\begin{array}{l}-0.3099 \\
(-5.1932)\end{array}$ & $\begin{array}{l}-0.0489 \\
(-4.2492)\end{array}$ & $\begin{array}{l}-0.5706 \\
(-9.6829)\end{array}$ & $\begin{array}{l}-0.0592 \\
(-4.8578)\end{array}$ & $\begin{array}{l}-0.3929 \\
(-6.5817)\end{array}$ & $\begin{array}{l}-0.054 \\
(-4.214)\end{array}$ & $\begin{array}{l}-0.3757 \\
(-12.027)\end{array}$ & $\begin{array}{l}-0.0467 \\
(-4.2645)\end{array}$ & $\begin{array}{c}-0.3155 \\
(-10.8489)\end{array}$ & $\begin{array}{l}-0.0544 \\
(-3.9721)\end{array}$ & $\begin{array}{r}-0.3118 \\
(-10.753)\end{array}$ \\
\hline CPI Inflation & $\begin{array}{l}0.5085 \\
(2.3129)\end{array}$ & $\begin{array}{l}-0.7681 \\
(-3.0421)\end{array}$ & $\begin{array}{r}0.3402 \\
{ }^{\prime}(2.7265)\end{array}$ & $\begin{array}{l}-1.3398 \\
(-5.1579)\end{array}$ & $\begin{array}{l}0 \\
0\end{array}$ & $\begin{array}{l}-1.3664 \\
(-4.9386)\end{array}$ & $\begin{array}{l}0 \\
0\end{array}$ & $\begin{array}{c}-0.7271 \\
(-3.0913)\end{array}$ & $\begin{array}{l}0 \\
0\end{array}$ & $\begin{array}{l}-1.2368 \\
(-3.7427)\end{array}$ & $\begin{array}{l}0 \\
0\end{array}$ & $\begin{array}{l}-1.4323 \\
(-6.8851)\end{array}$ & $\begin{array}{l}0 \\
0\end{array}$ & $\begin{array}{c}-1.956 \\
(-12.1407)\end{array}$ & $\begin{array}{r}0.2517 \\
.(1.4005)\end{array}$ & $\begin{array}{r}-1.9563 \\
(-12.6136)\end{array}$ \\
\hline Commondity Exporter & $\begin{array}{l}3.3631 \\
(3.0097)\end{array}$ & $\begin{array}{l}-3.9504 \\
(-1.5778)\end{array}$ & $\begin{array}{r}4.9486 \\
{ }_{(5.169)}\end{array}$ & $\begin{array}{c}-8.608 \\
(-4.6559)\end{array}$ & $\begin{array}{r}5.8598 \\
r_{(6.5732)}\end{array}$ & $\begin{array}{l}-10.899 \\
(-4.9385)\end{array}$ & $\begin{array}{r}5.5711 \\
r_{(4.9813)}\end{array}$ & $\begin{array}{l}-10.599 \\
(-6.2659)\end{array}$ & $\begin{array}{r}6.7602 \\
r_{(6.3355)}\end{array}$ & $\begin{array}{l}-16.429 \\
(-6.148)\end{array}$ & $\begin{array}{r}6.5774 \\
r_{(6.0743)}\end{array}$ & $\begin{array}{l}-16.944 \\
(-10.3465)\end{array}$ & $\begin{array}{r}6.0721 \\
{ }_{(6.7717)}\end{array}$ & $\begin{array}{r}-7.9959 \\
(-7.0227)\end{array}$ & $\begin{array}{r}5.9522 \\
{ }^{\prime}(5.5937)\end{array}$ & $\begin{array}{r}-7.8243 \\
(-6.9044)\end{array}$ \\
\hline Credit Market Regulation & & & 0 & $\begin{array}{c}-3.3415 \\
(-4.0569)\end{array}$ & $\begin{array}{l}-1.1917 \\
(-2.2671)\end{array}$ & $\begin{array}{c}-4.126 \\
(-4.9562)\end{array}$ & $\begin{array}{l}0 \\
0\end{array}$ & $\begin{array}{l}-4.5687 \\
(-5.537)\end{array}$ & $\begin{array}{l}0 \\
0\end{array}$ & $\begin{array}{r}-7.0479 \\
(-5.952)\end{array}$ & $\begin{array}{l}0 \\
0\end{array}$ & $\begin{array}{l}-6.8926 \\
(-6.8926)\end{array}$ & $\begin{array}{c}-1.319 \\
(-2.4603)\end{array}$ & $\begin{array}{r}-3.1081 \\
(-6.46)\end{array}$ & $\begin{array}{l}-1.1078 \\
(-1.9899)\end{array}$ & $\begin{array}{c}-3.067 \\
(-6.3408)\end{array}$ \\
\hline Stock Market Capitalization 2003-2006 & & & & & $\begin{array}{r}0.9682 \\
(2.1339)\end{array}$ & $\begin{array}{l}-2.5412 \\
(-2.6574)\end{array}$ & $\begin{array}{r}0.8956 \\
{ }_{(1.9121)}\end{array}$ & $\begin{array}{c}-2.951 \\
(-3.8383)\end{array}$ & $\begin{array}{l}1.7485 \\
\text { "(2.2968) }\end{array}$ & $\begin{array}{r}1.7485 \\
r_{(2.2968)}\end{array}$ & $\begin{array}{r}2.2616 \\
(3.3954)\end{array}$ & $\begin{array}{r}2.2616 \\
\quad(3.3954)\end{array}$ & $\begin{array}{r}1.0434 \\
(2.3101)\end{array}$ & $\begin{array}{l}-2.5143 \\
(-4.0451)\end{array}$ & $\begin{array}{r}1.1169 \\
\\
(2.2943)\end{array}$ & $\begin{array}{c}-2.446 \\
(-4.0555)\end{array}$ \\
\hline Bank Claim/Deposit Ratio & & & & & & & $\begin{array}{l}0 \\
0\end{array}$ & $\begin{array}{r}5.9549 \\
\quad \mathbf{r}_{(1.7322)}\end{array}$ & & & & & & & & \\
\hline Bank Nonperforming Loan Ratio & & & & & & & & & 0 & $\begin{array}{l}-0.8217 \\
(-3.5021)\end{array}$ & $\begin{array}{l}0 \\
0\end{array}$ & $\begin{array}{l}-0.9431 \\
(-5.9227)\end{array}$ & & & & \\
\hline Voice and Accountability Index & & & & & & & & & & & & & $\begin{array}{l}0 \\
0\end{array}$ & $\begin{array}{l}-6.2316 \\
(-7.8594)\end{array}$ & $\begin{array}{r}0.4157 \\
\quad(0.455)\end{array}$ & $\begin{array}{r}-6.2016 \\
(-7.8896)\end{array}$ \\
\hline Log of 2006 GDP per capita & & & & & & & & & & & & & & & $\begin{array}{c}0.555 \\
r_{(0.5536)}\end{array}$ & $\begin{array}{r}-0.1834 \\
-0.2494\end{array}$ \\
\hline Log of 2006 GDP per capita / & $\begin{array}{l}0.6021 \\
(2.8594)\end{array}$ & $\begin{array}{r}-0.6021 \\
(-2.8594)\end{array}$ & ${ }^{0.6363}$ & $\begin{array}{r}-0.6363 \\
(-2.9552)\end{array}$ & $\begin{array}{r}0.5192 \\
{ }^{\prime}(2.3257)\end{array}$ & $\begin{array}{r}-0.5192 \\
(-2.3257)\end{array}$ & $\begin{array}{r}0.5831 \\
(2.8498)\end{array}$ & $\begin{array}{r}-0.5831 \\
(-2.8498)\end{array}$ & ${ }^{0.7121}$ & $\begin{array}{c}-0.7121 \\
(-2.7156)\end{array}$ & $\begin{array}{r}0.7602 \\
(2.7292)\end{array}$ & $\begin{array}{r}-0.7602 \\
(-2.7292)\end{array}$ & $\begin{array}{r}0.6479 \\
r_{(2.8627)}\end{array}$ & $\begin{array}{r}-0.6479 \\
(-2.8627)\end{array}$ & $\begin{array}{r}0.6659 \\
\end{array}$ & $\begin{array}{r}-0.6659 \\
(-2.9219)\end{array}$ \\
\hline
\end{tabular}

Note: Point estimates appear in bold, z scores appear underneath 


\begin{tabular}{|c|c|c|c|}
\hline \multicolumn{4}{|c|}{ Table 7 - The Double Dip } \\
\hline \multirow[b]{2}{*}{ Variable } & \multicolumn{2}{|c|}{ Dependent = 2008-09 Growth } & \multirow{2}{*}{$\begin{array}{c}\text { Dependent }=\mathbf{2 0 1 2} \text { Growth } \\
\text { Class } 1\end{array}$} \\
\hline & Class 1 & Class 2 & \\
\hline Profile & 0.6589 & 0.3411 & - \\
\hline Obs & 92 & & 88 \\
\hline Rsq class & 0.5451 & 0.8265 & - \\
\hline Rsq Overall & 0.8021 & & 0.2121 \\
\hline \multirow[t]{2}{*}{ Current Account/GDP } & 7.0956 & 58.1518 & 1.19 \\
\hline & 1.7133 & 6.7223 & 0.4516 \\
\hline \multirow[t]{2}{*}{ Growth in Banking Credit } & -0.0391 & -0.3345 & -0.0199 \\
\hline & -3.1779 & -6.464 & -2.2923 \\
\hline \multirow[t]{2}{*}{ CPI Inflation } & 0.5085 & -0.7681 & 0.1466 \\
\hline & 2.3129 & -3.0421 & 1.5018 \\
\hline \multirow[t]{2}{*}{ Commondity Exporter } & 3.3631 & -3.9504 & 1.9848 \\
\hline & 3.0097 & -1.5778 & 3.1626 \\
\hline \multirow[t]{2}{*}{ Log of 2006 GDP per capita (covariate) } & 0.6021 & -0.6021 & - \\
\hline & 2.8594 & -2.8594 & \\
\hline
\end{tabular}

Note: Point estimates appear in bold, z scores appear underneath 


\begin{tabular}{|c|c|c|c|c|c|c|}
\hline \multirow[b]{3}{*}{ Variable } & \multicolumn{6}{|c|}{ Table 8 - Robustness Across Data/Crisis Episode } \\
\hline & \multicolumn{2}{|c|}{$\begin{array}{c}\text { Baseline - (RS } 2010 \text { Data) } \\
\text { Dep. Var. - 2008-09 Real GDPG rowth }\end{array}$} & \multicolumn{2}{|c|}{$\begin{array}{l}\text { Baseline - Updated Data } \\
\text { Dep. Var. - 2008-09 Real GDPGrowth }\end{array}$} & \multicolumn{2}{|c|}{$\begin{array}{l}1997 \text { Asian Crisis } \\
\text { Dep. Var - } 1998 \text { Real GDP Growth }\end{array}$} \\
\hline & Class 1 & Class 2 & Class 1 & Class 2 & Class 1 & Class 2 \\
\hline Profile & 0.6589 & 0.3411 & 0.527 & 0.473 & 0.6789 & 0.3211 \\
\hline Obs & 92 & & 90 & & 86 & \\
\hline Rsq class & 0.5451 & 0.8265 & 0.6919 & 0.4716 & 0.0643 & 0.4315 \\
\hline \multirow[t]{2}{*}{ Current Account/GDP } & 7.0956 & 58.1518 & -0.0272 & 0.4511 & -0.0228 & 0.5996 \\
\hline & 1.7133 & 6.7223 & -0.8257 & 2.3576 & -1.4782 & 3.7693 \\
\hline \multirow[t]{2}{*}{ Growth in Banking Credit } & -0.0391 & -0.3345 & -0.0619 & -0.1715 & -0.0064 & 0.0133 \\
\hline & -3.1779 & -6.464 & -6.8594 & -2.5277 & -0.7693 & 0.4729 \\
\hline \multirow[t]{4}{*}{ Log of 2006 GDP per capita (covariate) } & 0.6021 & -0.6021 & 0.7335 & -0.7335 & 0.6094 & -0.6094 \\
\hline & 2.8594 & -2.8594 & -2.2653 & 2.2653 & 2.8112 & -2.8112 \\
\hline & & & \multicolumn{2}{|c|}{ Baseline - Updated Data } & \multicolumn{2}{|c|}{1997 Asian Crisis } \\
\hline & & & \multicolumn{2}{|c|}{ Dep. Var. - 08-09 Growth - 5 yr Trend } & \multicolumn{2}{|c|}{ Dep. Var. - 1998 Growth - 5 yr Trend } \\
\hline Variable & & & Class 1 & Class 2 & Class 1 & Class 2 \\
\hline Profile & & & 0.6155 & 0.3845 & 0.6674 & 0.3326 \\
\hline Obs & & & 90 & & 86 & \\
\hline Rsq class & & & 0.4593 & 0.6266 & 0.3368 & 0.7011 \\
\hline Rsq Overall & & & 0.6546 & & 0.7286 & \\
\hline Commondity Exporter & & & 2.1889 & 0.4757 & -1.8561 & -3.9098 \\
\hline \multirow[t]{2}{*}{ Log of 2006 GDP per capita (covariate) } & & & 0.728 & -0.728 & 0.3852 & -0.3852 \\
\hline & & & 2.4377 & -2.4377 & 3.0803 & -3.0803 \\
\hline
\end{tabular}


Appendix 1 - Country Classification Tables

\begin{tabular}{|c|c|c|c|c|c|c|c|}
\hline \multicolumn{2}{|c|}{ Model 1} & \multicolumn{2}{|c|}{ Model 2} & \multicolumn{2}{|c|}{ Model 3} & \multicolumn{2}{|c|}{ Model 4} \\
\hline Cluster 1 & Cluster 2 & Cluster 1 & Cluster 2 & Cluster 1 & Cluster 2 & Cluster 1 & Cluster 2 \\
\hline Mean Growth & & Mean Growth & & Mean Growth & & Mean Growth & \\
\hline-0.2653 & 6.7677 & -0.5278 & 2.7584 & -0.0326 & 1.8644 & -0.4889 & 2.5855 \\
\hline Mean Income & & Mean Income & & Mean Income & & Mean Income & \\
\hline 9.7462 & 8.9735 & 9.7379 & 8.9193 & 9.6961 & 9.0135 & 9.719 & 8.9862 \\
\hline Algeria & Albania & Algeria & Albania & Argentina & China & Argentina & Egypt \\
\hline Argentina & Bahrain & Argentina & Bahrain & Armenia & Egypt & Armenia & Estonia \\
\hline Armenia & Belarus & Armenia & China & Australia & Estonia & Australia & Indonesia \\
\hline Australia & China & Australia & Dominican Rep & Austria & Kyrgyz Republic & Austria & Iran \\
\hline Austria & Dominican Rep & Austria & Egypt & Belgium & Latvia & Barbados & Kyrgyz Republic \\
\hline Belgium & Egypt & Belgium & Estonia & Botswana & Lithuania & Belgium & Latvia \\
\hline Botswana & Estonia & Botswana & Guyana & Brazil & Macedonia (FYR) & Botswana & Lithuania \\
\hline Brazil & Georgia & Brazil & Haiti & Bulgaria & Mexico & Brazil & Macedonia (FYR) \\
\hline Bulgaria & Guyana & Bulgaria & Jamaica & Canada & Morocco & Bulgaria & Mexico \\
\hline Canada & Haiti & Canada & Kyrgyz Republic & Chile & Namibia & Canada & Morocco \\
\hline Chile & Indonesia & Chile & Latvia & Colombia & Oman & Chile & Namibia \\
\hline Colombia & Jamaica & Colombia & Lithuania & Costa Rica & Panama & Colombia & Oman \\
\hline Costa Rica & Kyrgyz Republic & Costa Rica & Macedonia (FYR) & Croatia & Papua New Guinea & Costa Rica & Panama \\
\hline Croatia & Latvia & Croatia & Mexico & Cyprus & Paraguay & Croatia & Papua New Guinea \\
\hline Cyprus & Lithuania & Cyprus & Morocco & Czech Rep & Peru & Cyprus & Peru \\
\hline Czech Rep & Macedonia (FYR) & Czech Rep & Namibia & Denmark & Poland & Czech Rep & Poland \\
\hline Denmark & Morocco & Denmark & Oman & Ecuador & Russia & Denmark & Russia \\
\hline Ecuador & Oman & Ecuador & Panama & El Salvador & Turkey & Ecuador & Tunisia \\
\hline El Salvador & Panama & El Salvador & Papua New Guinea & Finland & Ukraine & El Salvador & Turkey \\
\hline Finland & Papua New Guinea & Finland & Paraguay & France & & Finland & Ukraine \\
\hline France & Peru & France & Peru & Georgia & & France & Uruguay \\
\hline Gabon & Poland & Gabon & Poland & Germany, West & & Georgia & \\
\hline Germany, West & Qatar & Georgia & Russia & Greece & & Germany, West & \\
\hline Greece & Tunisia & Germany, West & Turkey & Guyana & & Greece & \\
\hline Hong Kong & Turkey & Greece & Ukraine & Hong Kong & & Guyana & \\
\hline Hungary & Ukraine & Hong Kong & Uruguay & Hungary & & Hong Kong & \\
\hline Iceland & Uruguay & Hungary & & Iceland & & Hungary & \\
\hline Iran & Venezuela & Iceland & & Indonesia & & Iceland & \\
\hline Ireland & & Indonesia & & Iran & & Ireland & \\
\hline Israel & & Iran & & Ireland & & Israel & \\
\hline Italy & & Ireland & & Israel & & Italy & \\
\hline Japan & & Israel & & Italy & & Jamaica & \\
\hline Kazakhstan & & Italy & & Jamaica & & Japan & \\
\hline Korea & & Japan & & Japan & & Kazakhstan & \\
\hline Kuwait & & Kazakhstan & & Kazakhstan & & Korea & \\
\hline Libya & & Korea & & Korea & & Kuwait & \\
\hline Luxembourg & & Kuwait & & Kuwait & & Luxembourg & \\
\hline Macau & & Luxembourg & & Luxembourg & & Malaysia & \\
\hline Malaysia & & Malaysia & & Malaysia & & Malta & \\
\hline Malta & & Malta & & Malta & & Mauritius & \\
\hline Mauritius & & Mauritius & & Mauritius & & Netherlands & \\
\hline Mexico & & Netherlands & & Netherlands & & New Zealand & \\
\hline Namibia & & New Zealand & & New Zealand & & Paraguay & \\
\hline Netherlands & & Portugal & & Portugal & & Portugal & \\
\hline New Zealand & & Romania & & Romania & & Romania & \\
\hline Paraguay & & Singapore & & Singapore & & Singapore & \\
\hline Portugal & & Slovakia & & Slovakia & & Slovakia & \\
\hline Romania & & Slovenia & & Slovenia & & Slovenia & \\
\hline Russia & & South Africa & & South Africa & & South Africa & \\
\hline Saudi Arabia & & Spain & & Spain & & Spain & \\
\hline Seychelles & & Sri Lanka & & Sri Lanka & & Sri Lanka & \\
\hline Singapore & & Sweden & & Sweden & & Sweden & \\
\hline Slovakia & & Switzerland & & Switzerland & & Switzerland & \\
\hline Slovenia & & Thailand & & Thailand & & Thailand & \\
\hline South Africa & & Trinidad \& Tobago & & Trinidad \& Tobago & & Trinidad \& Tobago & \\
\hline Spain & & Tunisia & & Tunisia & & United States & \\
\hline Sri Lanka & & UK & & UK & & Venezuela & \\
\hline Swaziland & & United States & & United States & & & \\
\hline Sweden & & Venezuela & & Uruguay & & & \\
\hline Switzerland & & & & Venezuela & & & \\
\hline Thailand & & & & & & & \\
\hline Trinidad \& Tobago & & & & & & & \\
\hline & & & & & & & \\
\hline United States & & & & & & & \\
\hline
\end{tabular}




\begin{tabular}{|c|c|c|c|c|c|c|c|}
\hline \multicolumn{2}{|c|}{ Model 5} & \multicolumn{2}{|c|}{ Model 6} & \multicolumn{2}{|c|}{ Model 7} & \multicolumn{2}{|c|}{ Model 8} \\
\hline Cluster 1 & Cluster 2 & Cluster 1 & Cluster 2 & Cluster 1 & Cluster 2 & Cluster 1 & Cluster 2 \\
\hline \multicolumn{2}{|l|}{ Mean Growth } & \multicolumn{2}{|l|}{ Mean Growth } & \multicolumn{2}{|l|}{ Mean Growth } & \multicolumn{2}{|l|}{ Mean Growth } \\
\hline-0.6755 & 1.3426 & -0.709 & 2.3624 & -0.333 & -0.4165 & -0.5626 & -0.434 \\
\hline \multicolumn{2}{|l|}{ Mean Income } & \multicolumn{2}{|l|}{ Mean Income } & \multicolumn{2}{|l|}{ Mean Income } & \multicolumn{2}{|l|}{ Mean Income } \\
\hline \multicolumn{2}{|l|}{9.8385} & \multicolumn{2}{|l|}{9.8185} & \multicolumn{2}{|l|}{9.7662} & 9.7795 & 8.9814 \\
\hline Argentina & China & Argentina & China & Argentina & Brazil & Argentina & Brazil \\
\hline Armenia & Egypt & Armenia & Egypt & Armenia & China & Armenia & China \\
\hline Australia & Estonia & Australia & Estonia & Australia & Colombia & Australia & Colombia \\
\hline Austria & Georgia & Austria & Georgia & Austria & Egypt & Austria & Egypt \\
\hline Belgium & Latvia & Belgium & Latvia & Barbados & Estonia & Barbados & Estonia \\
\hline Brazil & Lithuania & Brazil & Macedonia (FYR) & Belgium & Georgia & Belgium & Georgia \\
\hline Bulgaria & Macedonia (FYR) & Bulgaria & Mexico & Botswana & Guyana & Botswana & Guyana \\
\hline Canada & Mexico & Canada & Morocco & Bulgaria & Jamaica & Bulgaria & Jamaica \\
\hline Chile & Morocco & Chile & Namibia & Canada & Kyrgyz Republic & Canada & Korea \\
\hline Colombia & Namibia & Colombia & Oman & Chile & Latvia & Chile & Kyrgyz Republic \\
\hline Costa Rica & Oman & Costa Rica & Panama & Costa Rica & Lithuania & Costa Rica & Latvia \\
\hline Croatia & Panama & Croatia & Paraguay & Croatia & Macedonia (FYR) & Croatia & Lithuania \\
\hline Czech Rep & Paraguay & Czech Rep & Russia & Cyprus & Mexico & Cyprus & Macedonia (FYR) \\
\hline Denmark & Peru & Denmark & Thailand & Czech Rep & Morocco & Czech Rep & Mexico \\
\hline Ecuador & Poland & Ecuador & Turkey & Denmark & Namibia & Denmark & Morocco \\
\hline El Salvador & Russia & El Salvador & Ukraine & Ecuador & Oman & Ecuador & Namibia \\
\hline Finland & Thailand & Finland & Uruguay & El Salvador & Panama & El Salvador & Oman \\
\hline France & Turkey & France & & Finland & Papua New Guinea & Finland & Panama \\
\hline Germany, West & Ukraine & Germany, West & & France & Paraguay & France & Papua New Guinea \\
\hline Greece & Uruguay & Greece & & Germany, West & Peru & Germany, West & Paraguay \\
\hline Hong Kong & & Hong Kong & & Greece & Poland & Greece & Peru \\
\hline Hungary & & Hungary & & Hong Kong & Russia & Hong Kong & Poland \\
\hline Iceland & & Iceland & & Hungary & Tunisia & Hungary & Russia \\
\hline Indonesia & & Indonesia & & Iceland & Turkey & Iceland & Tunisia \\
\hline Ireland & & Ireland & & Indonesia & Ukraine & Indonesia & Turkey \\
\hline Israel & & Israel & & Iran & & Iran & Ukraine \\
\hline Italy & & Italy & & Ireland & & Ireland & \\
\hline Japan & & Japan & & Israel & & Israel & \\
\hline Korea & & Korea & & Italy & & Italy & \\
\hline Kuwait & & Kuwait & & Japan & & Japan & \\
\hline Luxembourg & & Lithuania & & Kazakhstan & & Kazakhstan & \\
\hline Malaysia & & Luxembourg & & Korea & & Kuwait & \\
\hline Malta & & Malaysia & & Kuwait & & Luxembourg & \\
\hline Netherlands & & Malta & & Luxembourg & & Malaysia & \\
\hline Portugal & & Netherlands & & Malaysia & & Malta & \\
\hline Romania & & Peru & & Malta & & Mauritius & \\
\hline Singapore & & Poland & & Mauritius & & Netherlands & \\
\hline Slovakia & & Portugal & & Netherlands & & New Zealand & \\
\hline Slovenia & & Romania & & New Zealand & & Portugal & \\
\hline South Africa & & Singapore & & Portugal & & Romania & \\
\hline Spain & & Slovakia & & Romania & & Singapore & \\
\hline Sweden & & Slovenia & & Singapore & & Slovakia & \\
\hline Switzerland & & South Africa & & Slovakia & & Slovenia & \\
\hline Tunisia & & Spain & & Slovenia & & South Africa & \\
\hline UK & & Sweden & & South Africa & & Spain & \\
\hline United States & & Switzerland & & Spain & & Sri Lanka & \\
\hline Venezuela & & Tunisia & & Sri Lanka & & Sweden & \\
\hline & & & & Sweden & & Switzerland & \\
\hline & & United States & & Switzerland & & Thailand & \\
\hline & & Venezuela & & Thailand & & Trinidad \& Tobago & \\
\hline & & & & Trinidad \& Toba & & & \\
\hline & & & & UK & & United States & \\
\hline & & & & United States & & Uruguay & \\
\hline & & & & Uruguay & & Venezuela & \\
\hline & & & & Venezuela & & & \\
\hline
\end{tabular}

